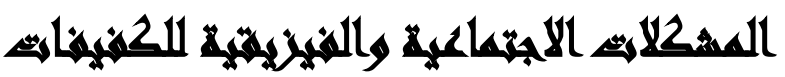

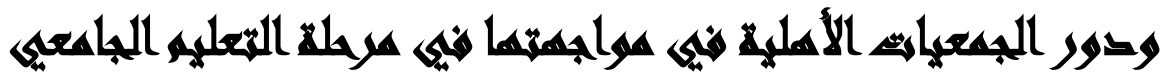

[1.]

فاتن إبراهيم عفيفي علي الجندي(')- علي محمود ليلة(r)- سهير عادل العطار (†) آنان

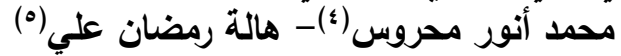

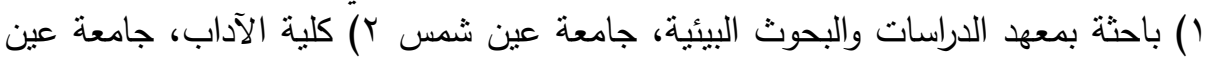

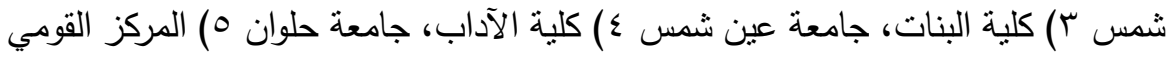

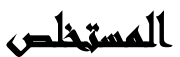

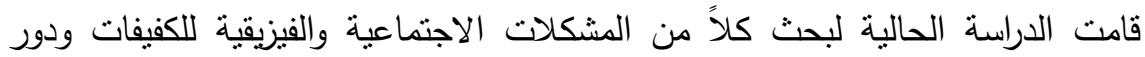

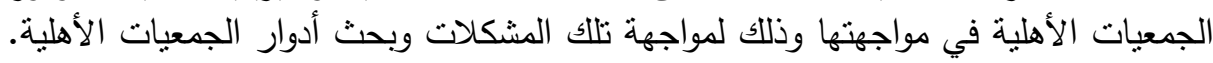

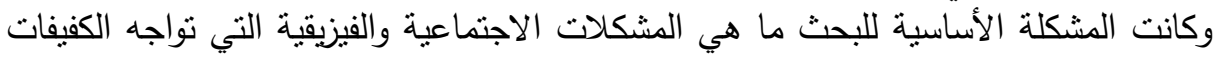

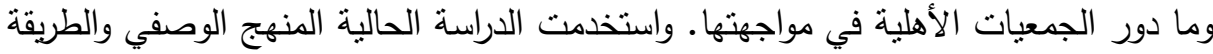

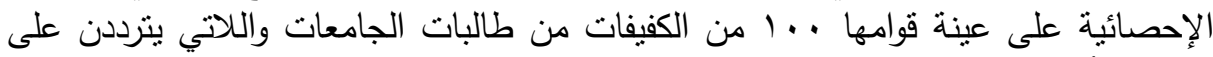

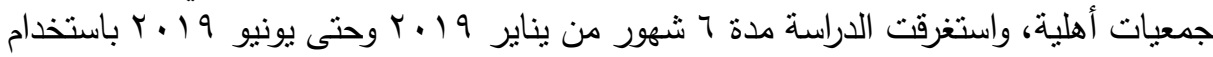
صحيفة استبيان كأداة أساسية لجمع بيانات الدراسة الداسة.

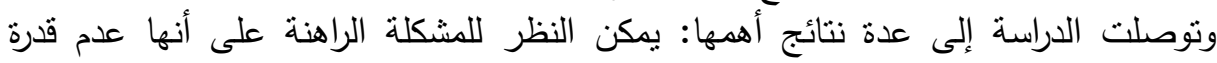

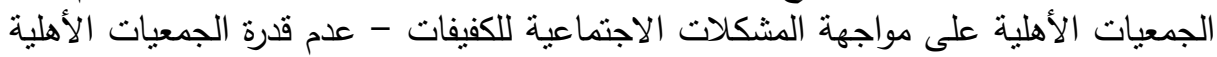

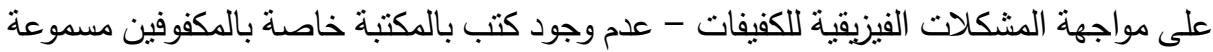

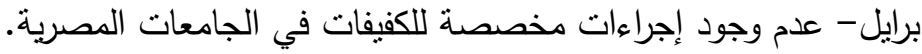

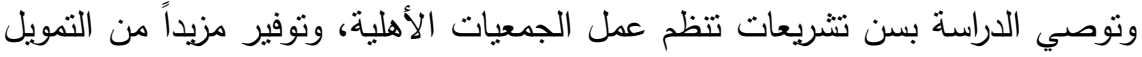

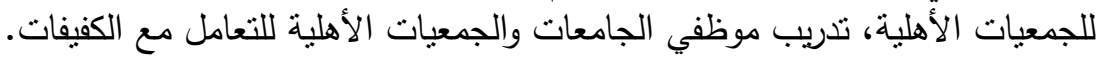

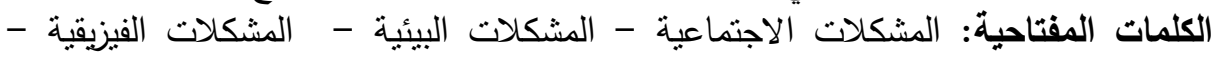
الكفيفات / المكفوفات - الكفيف / المكفوف - تعليم جامعي- - الجمعيات الأهلية. 


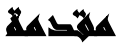

مما لا شك فيه إن المكفوفين جزء لا يتجزأ من المجتمع، ويشمل ذللك قيامهم بالواجبات

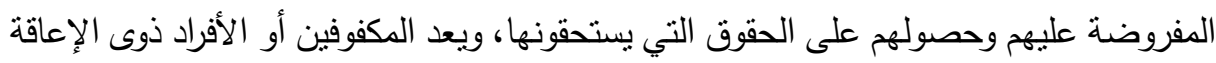
الحسية هم الأفراد الذين يبعدون عن الفرد المتوسط بعدا واضحا في قدراتهم الحسية وقدرات الاتصال والتواصل، الأمر الذي يجعل الفرد غير قادر على التكيف مع المنطلبات المدرسية والحياتية وحده، بحيث يترتب على ذلك حاجتهم إلى نوع من الخدمات والرعاية التربوية لتمكنهم

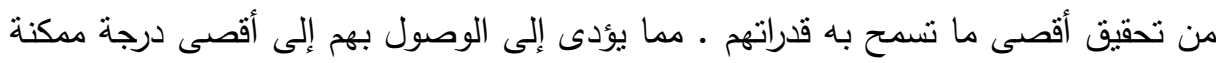

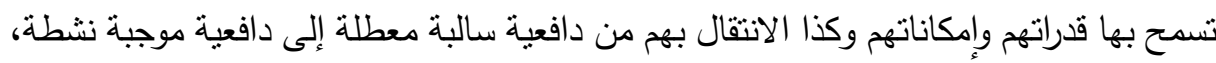
أما السبب فيرجع لأهمية وخطورة بل حتمية السعي لزيادة الوعي العام بهذه القضية، والتوجه

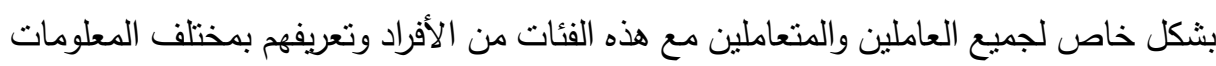
والجوانب المتعلقة بهم، وذلك لما يمكن أن يترتب على هذا التوجه من نتائج وآنار ايجابية.

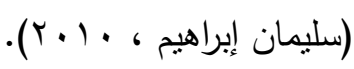

ومن ما يقدمه المجتمع للمكفوفين، قيام بعضاً من أفراده أو مؤسساته (الأهلية أو الحكومية)

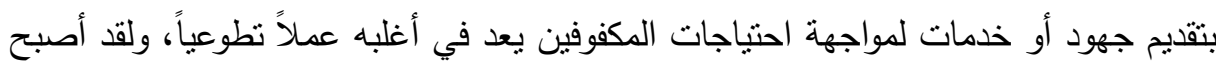
العمل التطوّعي ركيزة أساسية من ركائز بناء المجتمعات .. وأحد متطلبات الحياة الاجتماعية والاقتصادية والثقافية....(من موقع محطات العمل التطوعي) ومن المسلم به إن عدم إثباع احتياجات المكفوفين تؤدي إلى حدوث مشكلات عديدة لديهم منها الفيزيقية ومنها الاجتماعية ، وتقوم هذه الدراسة على إلقاء الضوء على إنى بعض المشكلات الاجتماعية وتتمل (مشكلات شخصية - مشكلات أسرية - مشكلات مع الأصدقاء والزملاء مشكلات مع المعلمين ) وبعض المشكلات الفيزيقية وتتثمل (بيئة المسكن - بيئة المنطقة السكنية أو الحي - ببيئة المدرسة أو الجامعة ) والتي قد تواجه الكفيفات ودور الجمعيات الأهلية في مواجهة نلاك المشكلات سالفة الذكر . والطلاب المكفوفين كغيرهم من الزملاء المبصرين لهم رغبة قوية في أن يصبحوا جزءً من

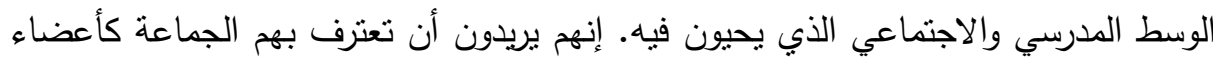

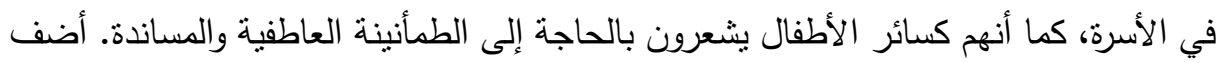


إلى هذا أن هؤلاء المكفوفين ما هم إلا أفراد يختلفون عن غيرهم من المصابين بنفس إعاقتهم

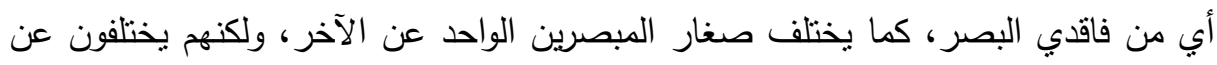
الأطفال المبصرين في أنهم في احتكاكهم بالوسط المحيط بهم وفي مواجتهم لظروف الحهات الحياة

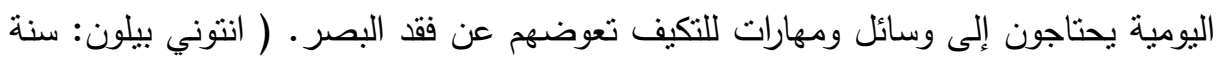
النشر غير مبينة).

ويجب على هيئة المدرسة أن تدرك أن فقد البصر قد يؤثر في نمو الطفل تأثثراً عكسياً،

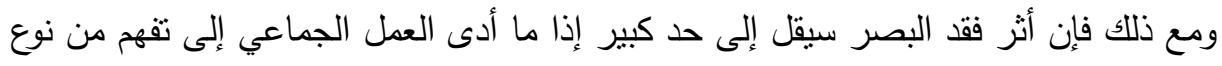
ما ومساعدة بساندها اتخاذ مواقف واقعية نحو الطفل. وفي منل هذا الجو يواجه الطفل بكل

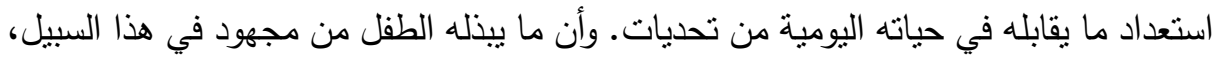

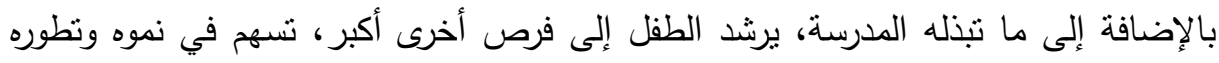

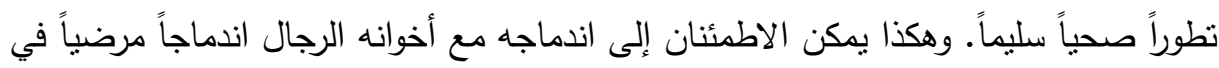
نهاية الأمر • ( انتوني بيلون : سنة النشر غير مبينة).

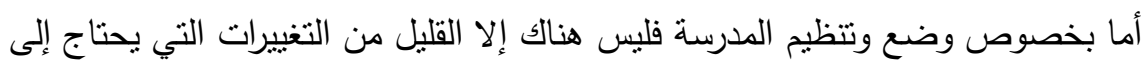
إدخالها حتى نتاسب الطفل الكفيف. بل إن الأمر يتعلق أكثر بمحاولة الطفل الكفيف تكييف

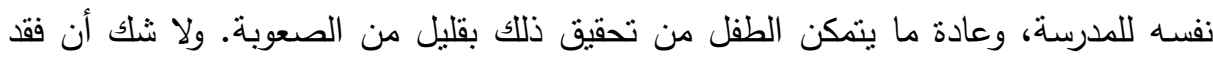
البصر يتسبب في إيجاد القليل من المشكلات التي يمكن حلها بطريقة عملية إذا ما قامت هيئة التدريس باستتباط الوسائل الكفيلة بحلها على الفور وقامت بإرشاد الطفل الكفيف لطريقة الحل.

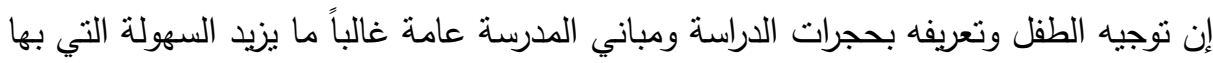
يسنطيع أن يتحرك دون مساعدة. ( انتوني بيلون: سنة النشر غير مبينة).

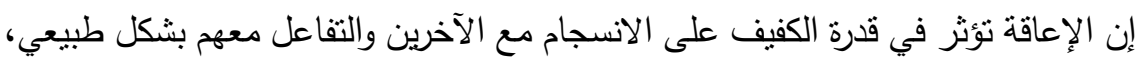
والاستمتاع بوقت الفراغ حيث يتطلب ذلك منه طاقات خاصة لا تتوفر عنده.

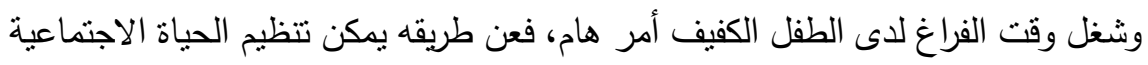

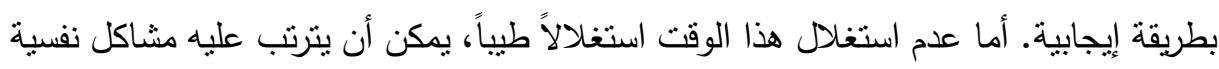
واجتماعية في حياته، لأنه يصبح منسماً أكثر بالسلبية، حيث يضفي المربون أهمية جوهرية 
على اللعب للطفل الكفيف، لأن اللعب هو خير وسيلة ليكون الفرد أكثر صفاء وروحانية. وفي

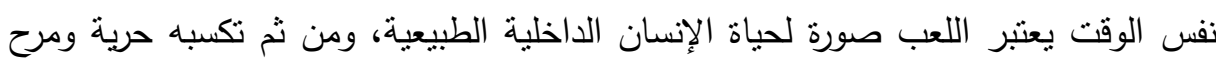

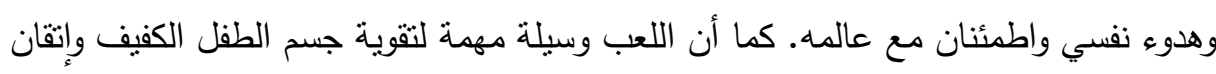
عملية الانتكثاف لديه وتوسيع خبراته وتكوين قيمه الخلقية.

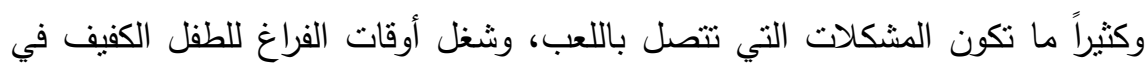

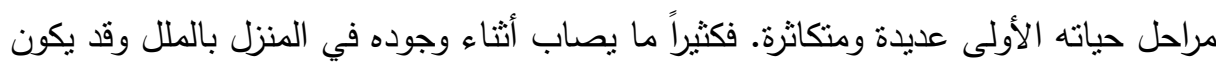

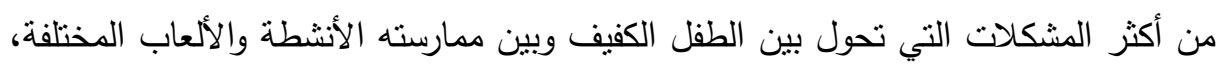

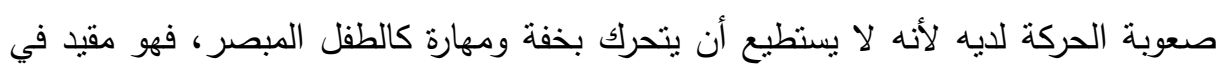

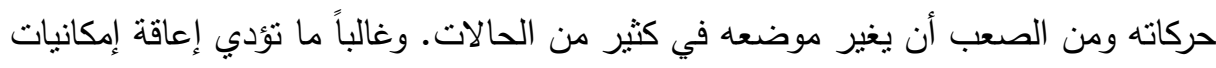

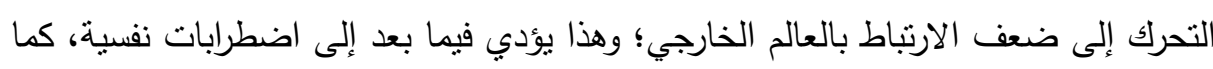

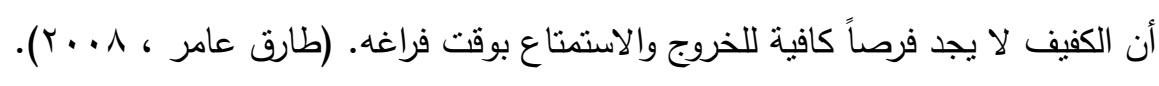

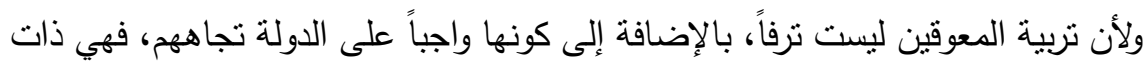

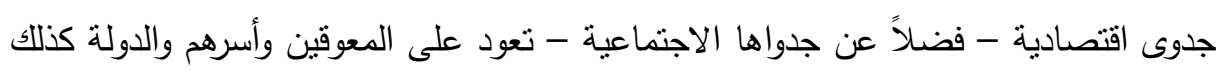

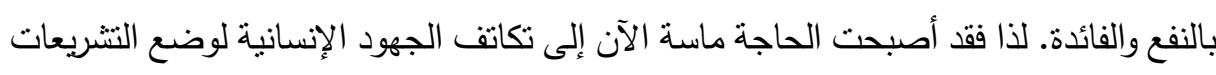

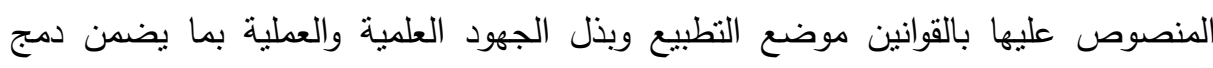

$$
\text { المعوقين في المجتمع ليساهوا في بنائه ورخائه. (رانيا الجمال ، 9. . ب). }
$$

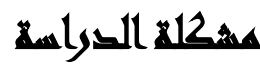

تحاول الدراسة الحالية إلقاء الضوء على المشكلات الاجتماعية والفيزيقية التي تواجه

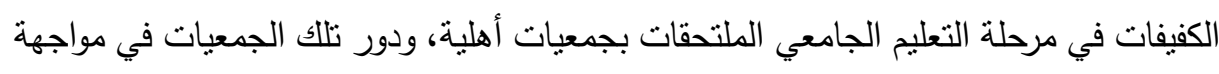
هذه المشكلات الاجتماعية والفيزيقية. ويمكن صياغة مثكلة الدراسة كما يلي: ماهية المشكلات الاجتماعية والفيزيقة للكفيفات

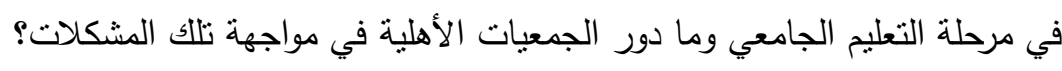

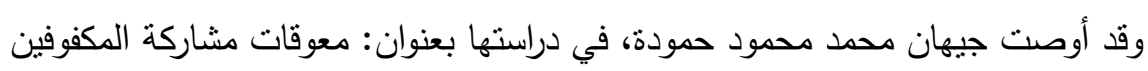

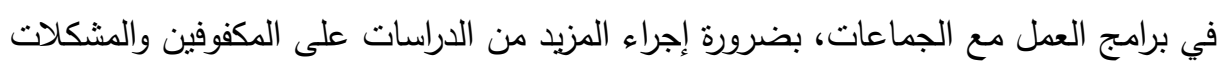

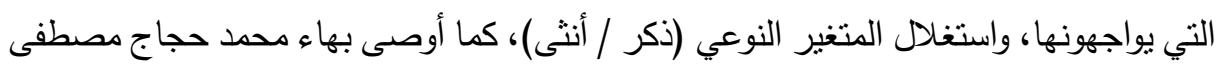


في دراسته بعنوان : تطور مراكز الرعاية لذوي الإعاقة البصرية بالجامعات المصرية في ضوء

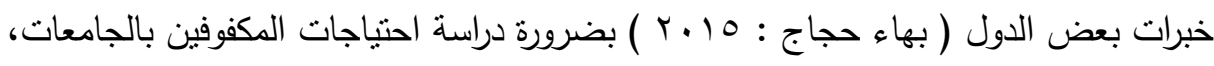

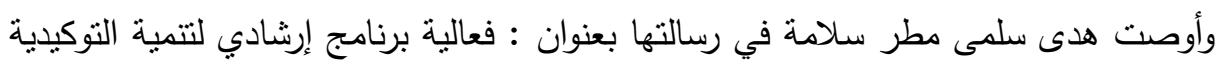

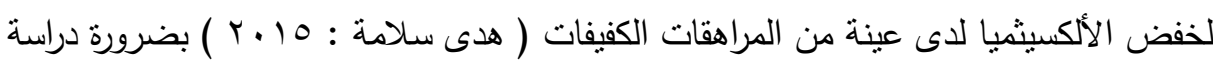

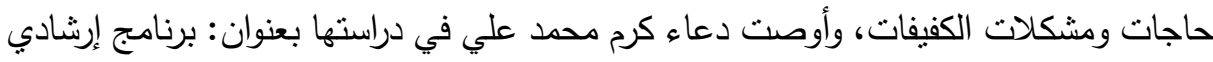

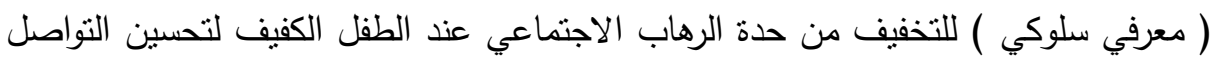

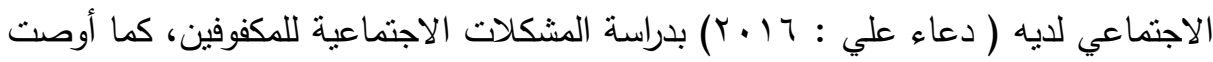

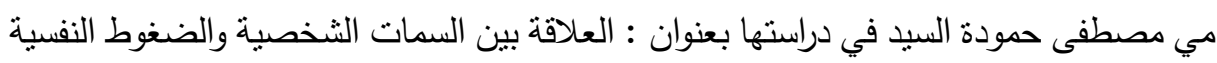

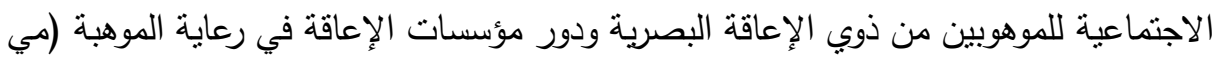

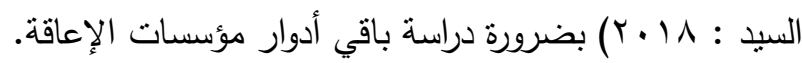

\section{توساولاهي الترواسة}

ا - ما المشكلات الاجتماعية للكفيفات في مرحلة التعليم الجامعي؟

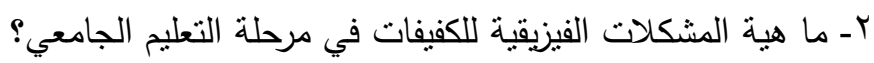

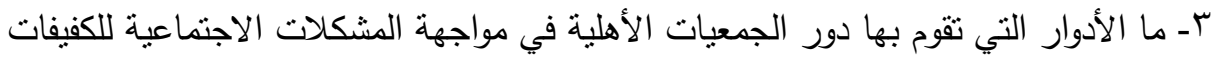

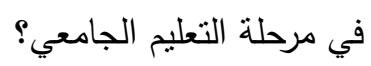
ع- ما الأدوار التي ثقوم بها الجمعيات الأهلية في مواجهة المشكلات الفيزيقية للكفيفات في

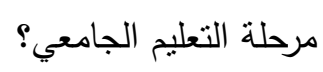

\section{أهصا اهن الكواسمة}

يتمنل الهدف الرئيسي للاراسة الحالية في محاولة التعرف على المشكلات الاجتماعية والفيزيقية للكفيفات في مرحلة التعليم الجامعي، والتعرف على دور الجمعيات الأهلية في مواجهة

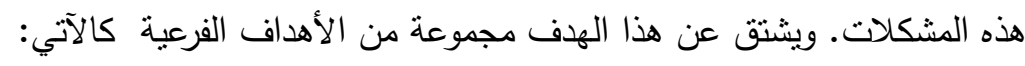
1 - إلقاء الضوه على المشكلات الاجتماعية للكفيفات في مرحلة التعليم الجامعي. r- إلقاء الضوء على المشكلات الفيزيقية للكفيفات في مرحلة التعليم الجامعي. 
r- إلقاء الضوء على دور الجمعيات الأهلية في مواجهة المشكلات الاجتماعية للكفيفات في مرحلة التعليم الجامعي.

ع - إلقاء الضوء على دور الجمعيات الأهلية في مواجهة المشكلات الفيزيقية للكفيفات في مرحلة

$$
\text { التعليم الجامعي. }
$$

\section{مشوض التوراسم}

الحدود الزمنية للاراسة: وقد قامت الدراسة الحالية في الفترة من 19/1/1 بـ وحتى

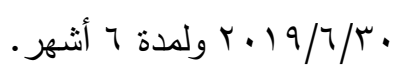

الحدود المكانية للاراسة: وقد شملت الدراسة على عينة مكونة من الكفيفات المنتميات للجمعيات الأهلية واللاتي يدرسن في الجامعات المصرية بإقليم القاهرة الكبرى (القاهرة - الجيزةالقليوبية).

\section{منهمج الصوراسلة}

تعتبر الدراسة الحالية من الدراسات الوصفية والتي تستخدم كلاً من المناهج التالية:

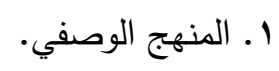
r l - الأسلوب الإحصائي لمعالجة البيانات.

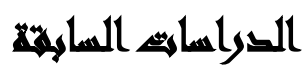

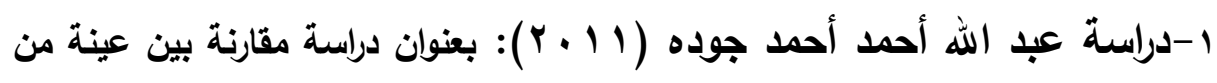
المكفوفين المقيمين في المؤسسة والمقيمين مع أسرهم على التوافق النفسي والاجتماعي

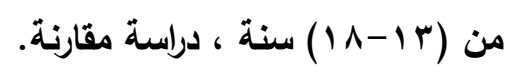

ركزت الدراسة على الفروق بين الأطفال المكفوفين من الجنسين المقيمين في المؤسسة المنة

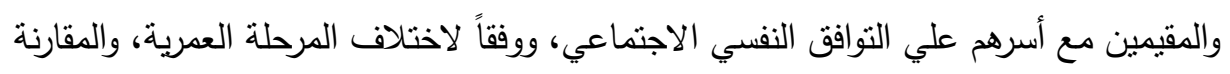

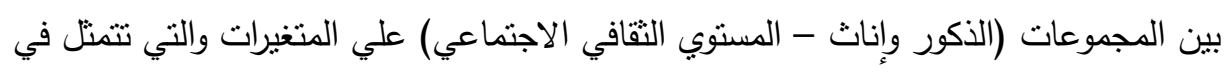
نوعية الإقامة، والنتوافق النفسي الاجنماعي. 


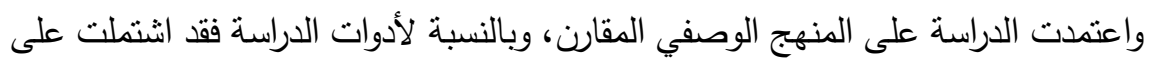

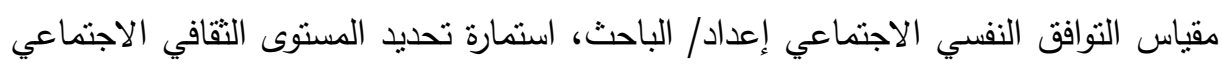

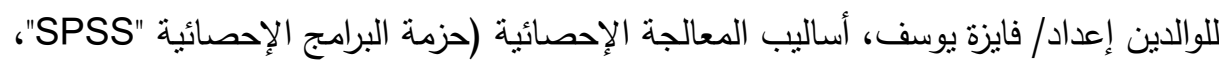
معامل الارتباط (ر) بيرسون لحساب ثنات مقياس (النوافق النفسي الاجتماعي)، تطبيق معادلة

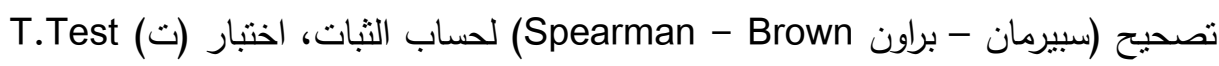
لتحديد مستوى دلالة الفروق بين المجموعات، تحليل التباين الأحادي ANOVA' one way لتحديد مستوى دلالة الفروق بين المجموعات العمرية، والمستوى النقافي الاجتماعي للوالدين). وكانت عينة الدراسة قوامها (101) طالب وطالبة من طلاب المرحلة الإعدادية والمرحلة

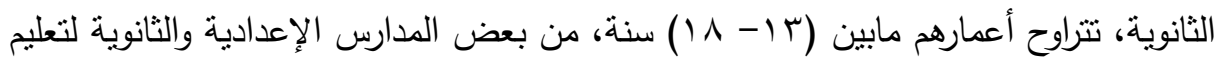
المكفوفين وضعاف البصر بمحافظة القاهرة والجيزة، ومن مستويات ثقافية-اجتماعية مختلفة. وقد أسفرت نتائج الدراسة عن الآتي: وجود فروق دالة إحصائيًا بين متوسطي درجات كل من ونات

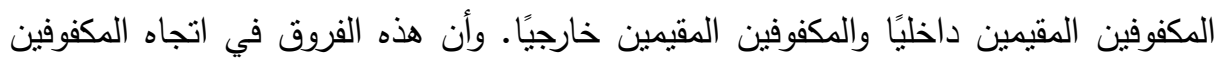
المقيمين مع أسرهم، لا توجد فروق دالة إحصائيًا بين متوسطي درجات كل من المكفوفين الذكور والمكفوفات الإناث على النوافق النفسي الاجتماعي للمكفوفين، وجود فروق دالة إحصائيًا بين متوسطي درجات المكفوفين فى التوافق النفسي الاجتماعي باختلاف المستويات الاجتماعية

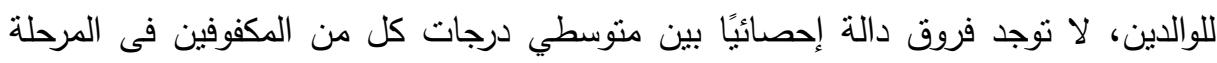

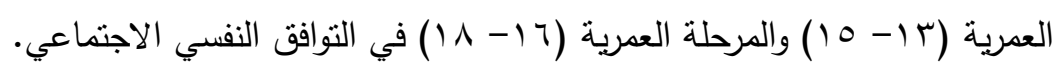

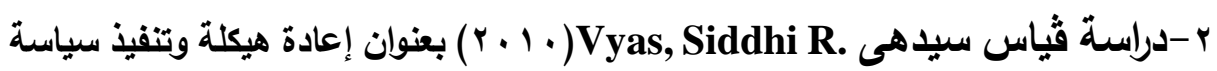
التعليم القومي من خلال المنظمات غير الحكومية:(NGO): إدراج التعليم في السياسة

وممارسات المدارس الابتدائية تجاه المكفوفين في الهند، دراسة وصفية تحلئية الئية.

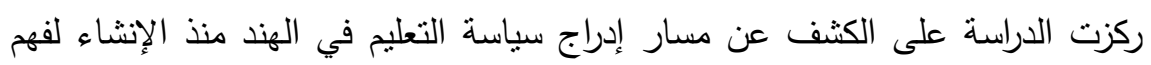
وتوضيح أهميتها في المدارس النظامية وداخل الفصول المدرسية و تطوير وإعادة هيكلة السياسة على المستوي التقليدي المتعارف عليه فيما يتعلق بصياغتها وتنفيذها للتعرف علي التأثيرات المحلية علي السياسة، والكثف عن ودراسة المجتمعات المشاركة للممثلين علي كل مستوي من 
منظمات المجتمع المدني والمدارس داخل سياقها الاجتماعي - الثقافي وتقوم الدراسة أولاً بدراسة التأثيرات الناجمة عن (وراء) تكوين أو هيكلة السياسة القومية للأثخاص ذوبي الإعاقات في الهند و ثانيا الكثف عن تتفيذ السياسة من خلال مبادرة التعليم القومي للطلاب ذوبي الاحتياجات الخاصة علي المستوى المدرسي من خلال التركيز تحديداً علي طلاب المدارس الابتدائية للمكفوفين. واعتمدت الدراسة على المنهج: الاجتماعي النقافي لتحليل المحتوى السياسي كما ناقنها كلاً من ساتون وليفنسون Sutton \&Levinson2001. ويالنسبة لأدوات الدراسة قد اشتملت

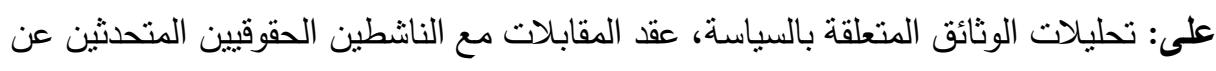
الإعاقة، تحليل الملاحظات المدرسية (الفصلية) والمقابلات التي عقدت مع الطلاب النظاميين

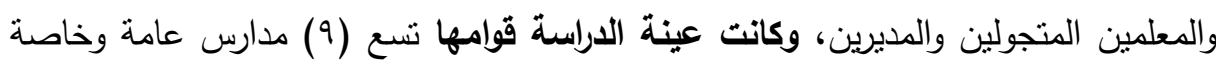
في مومباي وأحمد آباد بالهند. وقد أسفرت نتائج الاراسة عن : وجود موضوعيين أساسيين يصدران عن ومن خلا حل حوارات التطوير والتدريس التي تعكس وتتعكس علي حالة التعليم الابتدائي في الهند من خلال الدور

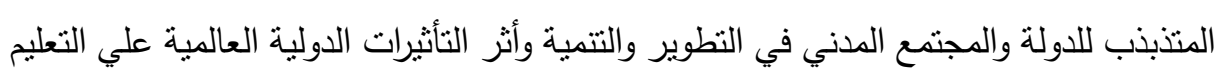

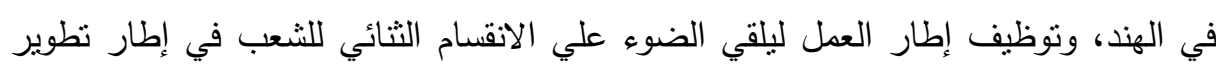
المبادرات الابتكارية الحديثة لسياسة التعليم القومي والمرنبطة بالممارسات العالمية والتي لا تزال التوال منفصلة عن السياقات المحلية وفق التأثيرات غير السياقية المرتبطة بالغرب.

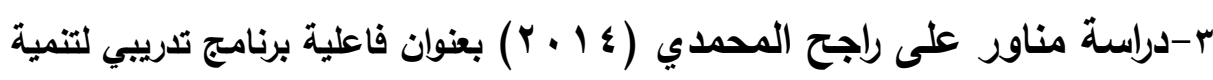

بعض مهارات التوجه والحركة لدى الأطفال ذوي الإعاقة البصرية، دراسة تجرية الجريبية.

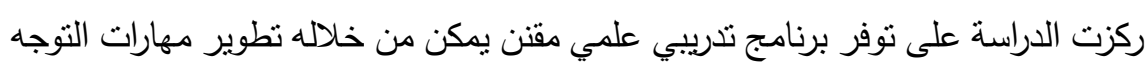
والحركة لاى الأطفال ذوي الإعاقة البصرية.

ويالتالي يمكن صياغة مشكلة الاراسة فى الأهداف الآتية: 1-توجد فروق دالة إحصائيا بين متوسطي رتب درجات أفئه أفراد المجموعة التجريبية والمجموعة الادية الضابطة في القياس القبلي لمقياس التوجه والحركة للأطفال ذوي الإعاقة البصرية. 
r-توجد فروق دالة إحصائياً بين متوسطي رتب درجات أفراد المجموعة التجريبية في القياسيين القبلي والبعدي لمقياس التوجه والحركة للأطفال ذوبي الإعاقة البصرية في اتجاه القياس البعدي. r-توجد فروق دالة إحصائياً بين متوسطي رتب درجات أفراد المجموعة التجريبية في القياسين البعدي والتتبعي لمقياس التوجه والحركة للأطفال ذوبي الإعاقة البصرية. وتعتمد الدراسة على المنهج التجريبي وبالنسبة لأدوات الدراسة فقد اشتنملت على مقياس الإسه

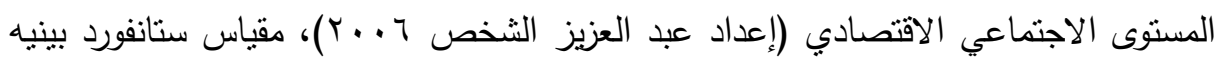
للاكاء (الصورة الرابعة: تعريب لويس كامل مليكه، 991 (1)، اختبار مهارات التوجه والحركة التهات

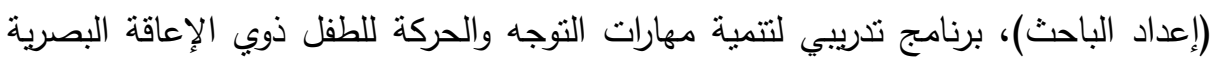

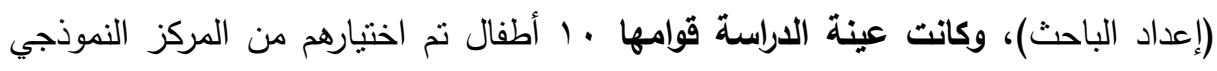
وتوجيه المكفوفين بالزيتون بمحافظة القاهرة. وقد أسفرت نتائج الدراسة عن: وجود فروق دالة إحصائياً بين متوسطي رتب درجات أفراد أفراد المجموعة التجريبية قبل وبعد تطبيق البرنامج على أبعاد مقياس مهارات التوجه والحركة للأطفال

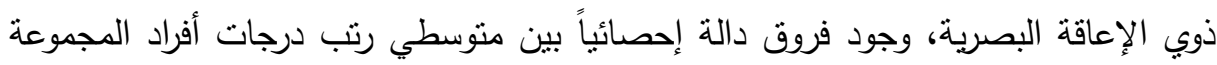

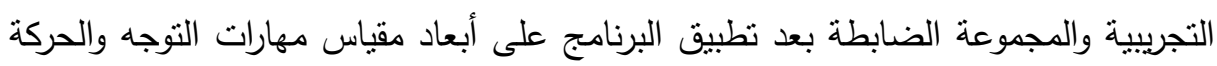

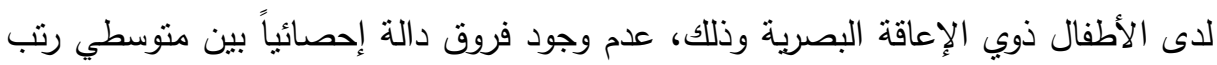
درجات أفراد المجموعة التجريبية على أبعاد مقياس مهارات التوجه والحركة.

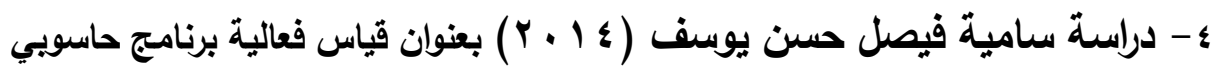
مقترح لتنمية مهارات استخدام المكتبات الجامعية للطلاب المكفوفين، دراسة تجريبية.

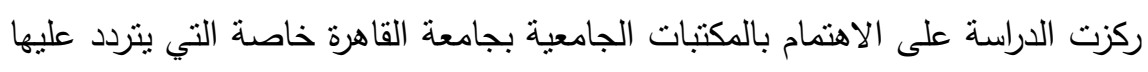

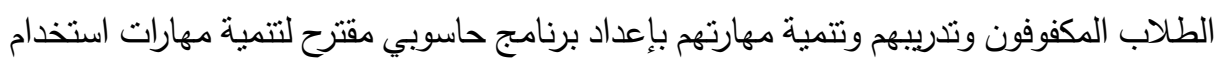
المكتبات الجامعية لاى الطلاب المكفوفين للبحث باستقلالية تامة وفق إمكانياتهم الآتية ووفقا لرغباتهم واحتياجاتهم الفعلية دون التقبد بمرافق ودون الحاجة لأخصائي المكتبة. 
ويالتالي يمكن صياغة مشكلة الدارسة في الأهداف الآتية: 1-فاعلية البرنامج الحاسوبي المقترح على تتمية مهارات استخدام المكتبات للطلاب الدكفوفين.

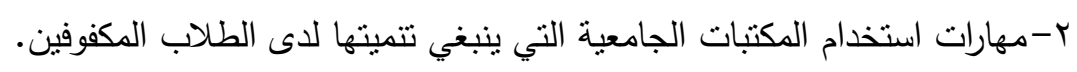

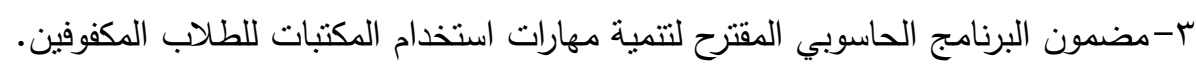

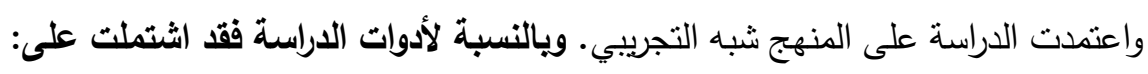

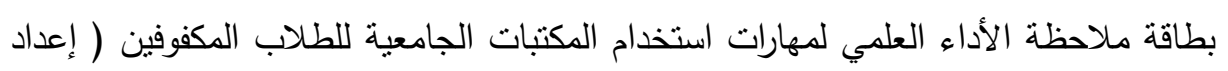

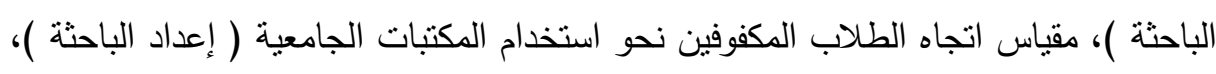

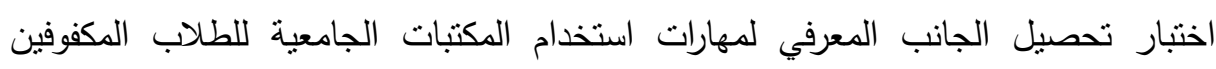

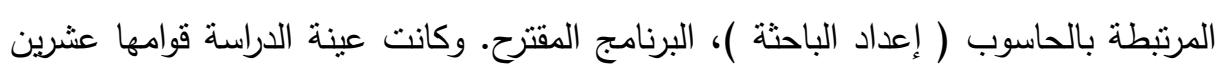

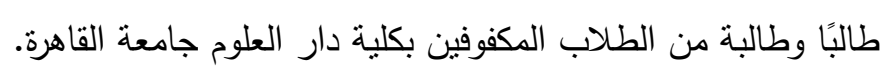

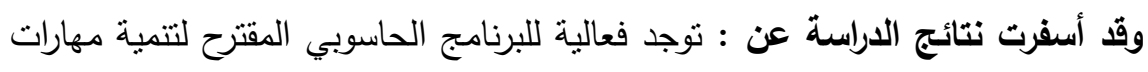

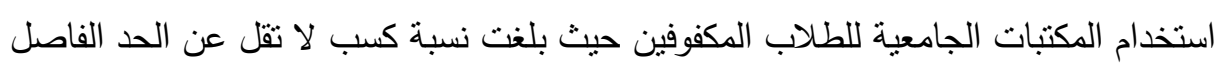

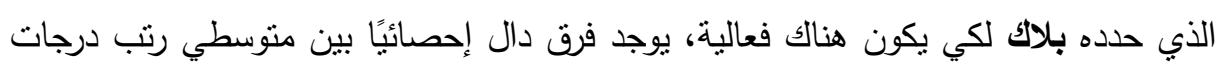

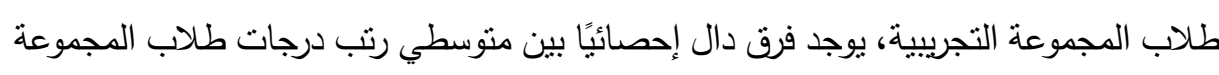

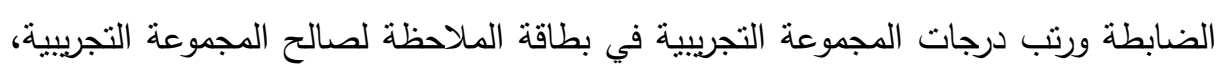

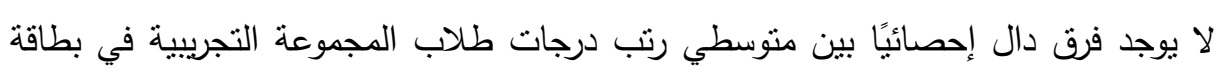

الملاحظة.

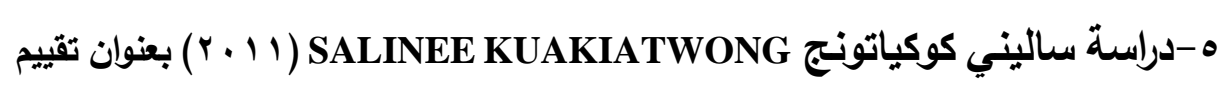
استخدام المكفوفين للإنترنت في جامعة سايبر تايلاند، دراسة مقارنة.

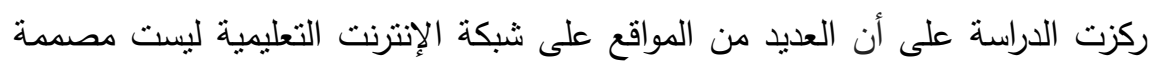

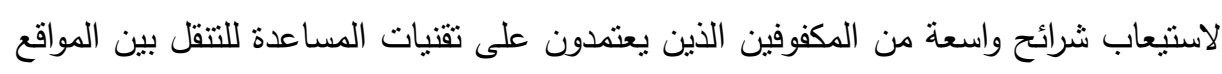

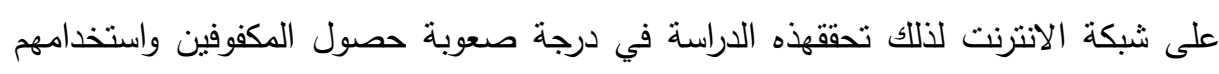
للموارد التعليمية على شبكة الإنترنت المقدمة من جامعة تايلاند سايير . 
وبالنسبة لأدوات الدراسة فقد اشتملت على أداة تحليل البيانات لبيانات تم جمعها على مرحلتين؛ ثم جمع البيانات الكمية أولا بهدف تحديد مشاكل إمكانية الوصول ومستويات التوافق لقات

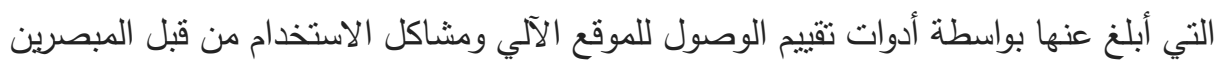

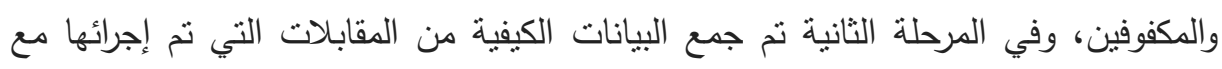

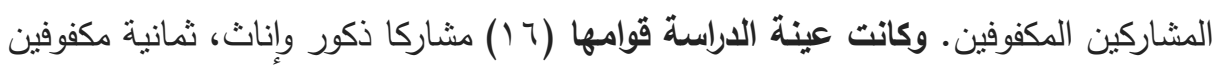

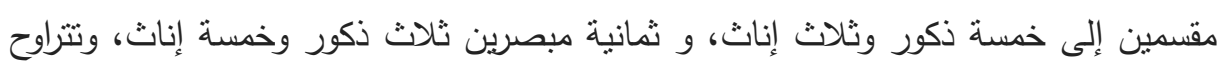
أعمار المشاركين ما بين 11 - ب ب سنة، و نتراوح سنوات الخبرة لدى المشاركين في الكمبيوتر

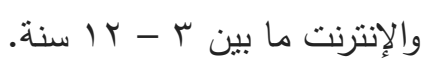

وقد أسفرت نتائج الاراسة عن: أن تقييم كل من صفحات الويب فنثلت في اجتياز الحد

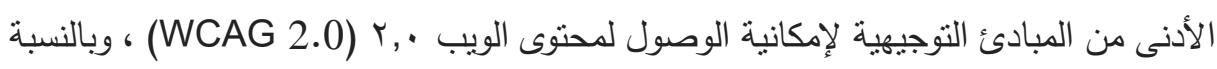

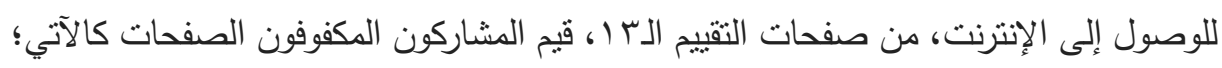

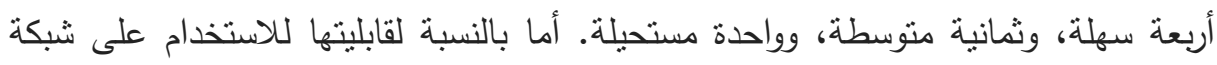

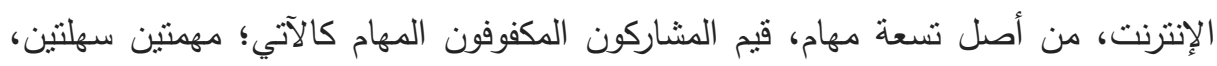
ومهونين متوسطنين، وخمسة مهام صعبة.

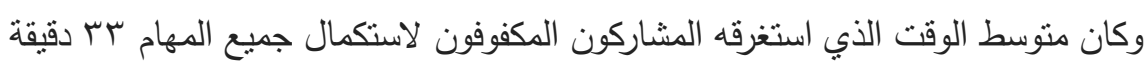
و جب ثانية. فقد أمضوا معظم وقتهم على تحديد الصفحة الأولى (الصفحة الرئيسية) فقد استغرقت

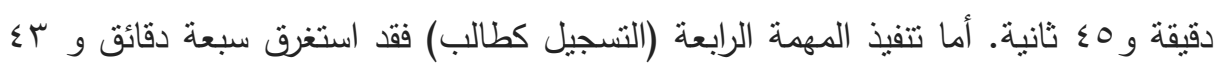

\section{الإطار اللنظيه}

لقد ظل المكفوفين في عالمنا العربي ردحا طويلا من الزمن محصورين في زاوية وظيفية

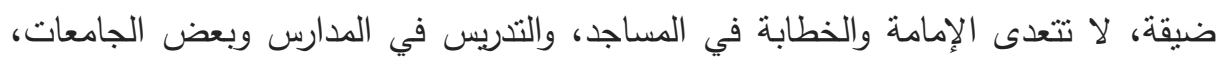

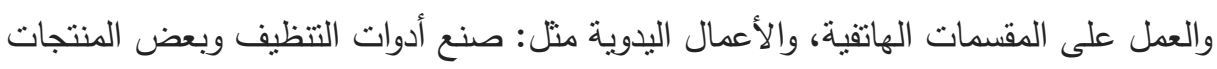
الخزفية، ووصلت في أبعد مدى لها إلى التخصص في مجال التصله المحاماة. 
في الوقت ذاته بلغ المكفوفين في دول العالم المتقدم شأنا بعيدا في هذا المضمار ، حيث

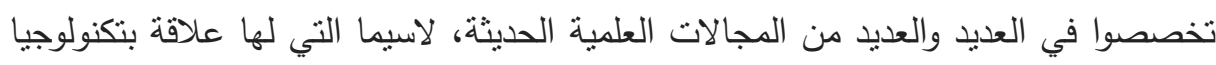

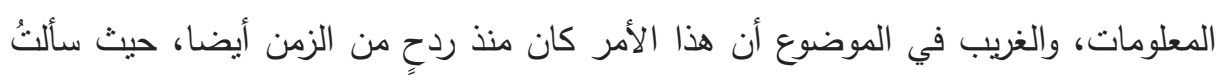

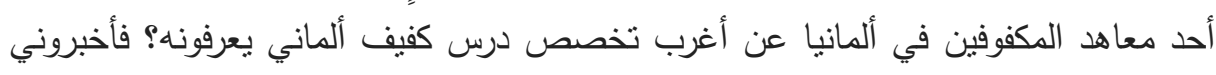
عن كفيف يعمل في تخصص هندسة القطارات وكان هذا منذ أربعين سنة.

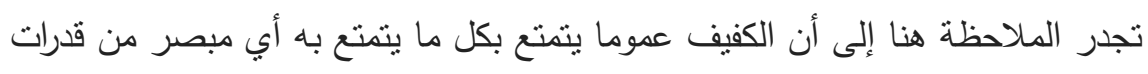

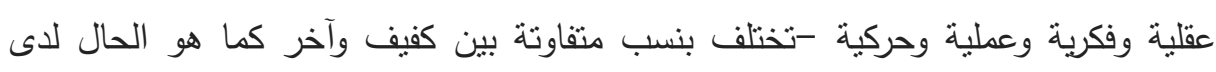

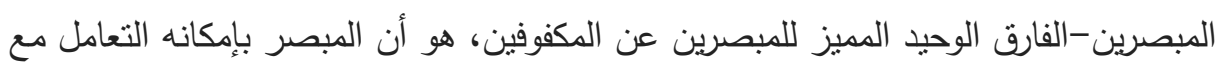

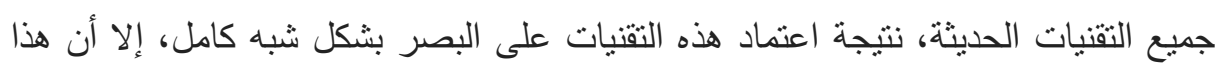

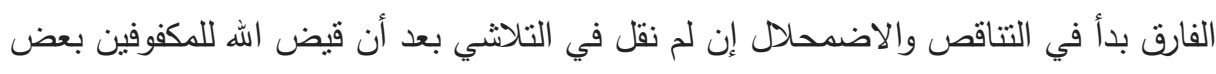

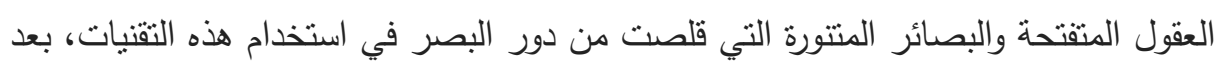

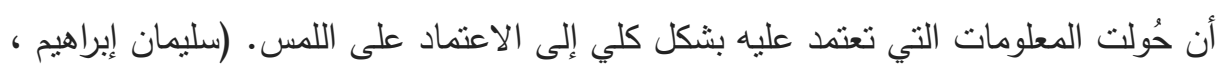
حاجات المعاقين بصرياً: إن الطفل المعاق بصريا هو طفل قبل كل شيء " يحتاج إلي ما

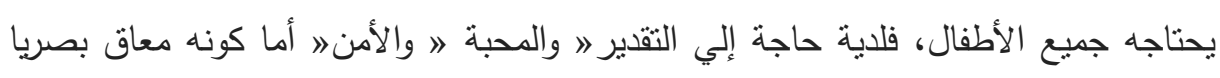

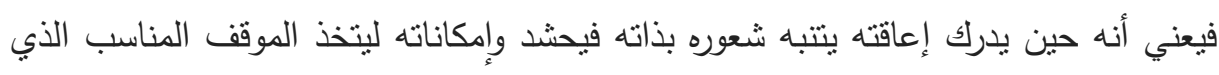
يعوضه عما فقده.

ويتفق علماء النفس علي وجود مجموعة من الحاجات الأساسية التي يعتبر إرضاؤها

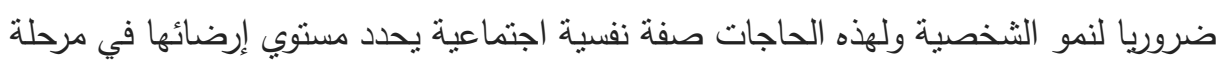

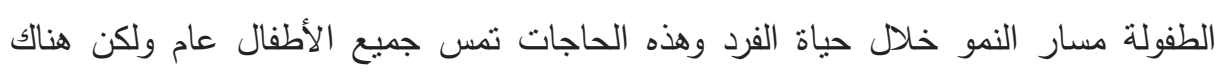
مجموعة من الحاجات تحص الأطفال المعاقين ومن أهم هذه الحاجات ما يلي:

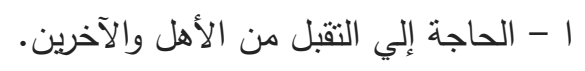
r-الحاجة إلي الاعتراف بالطفل بالرغم من اختلافه عن الآخرين. ب-الحاجة إلي الرعاية والمساعدة لبلوغ الاستقلالية. 
وتلبية هذه الحاجات يمكن أن يشعر الطفل بأنه محبوب من قبل الأهل والمجتمع كما ان

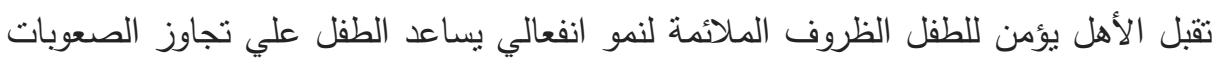
التي تلاقيه.

وهناك مجموعة من الاحتباجات الفردية التي لابد من توافرها للمعاق بصريا لتحقيق إحساسه بالأمن تعرضها سميرة نجدي( • 199 : V ) كما يلي:

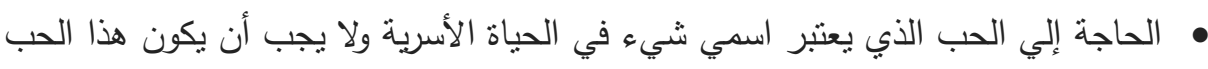

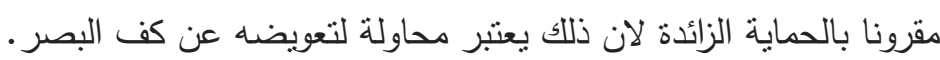

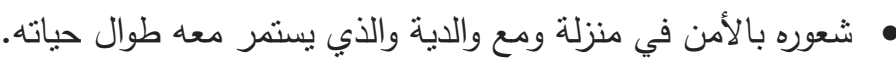

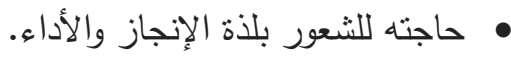
• اكتساب المعرفة أدراك العناصر الموجودة في البيئة من خلال معايشته لخبرات متعددة. • • • • • • • • ممارسة الحوار معه والقراءة له وتسمية والألعاب والأدوية التي في متتاول يده. • أن يتعلم من خلال أتلمس معاني جديدة ( الخشونة - النعومة -البرودة ) • • التمبيز بين الأطعمة المختلفة. • الإحساس بالثقة في النفس والأمان من المخاوف فالطفل المعاق بصريا يخاف من الأصوات

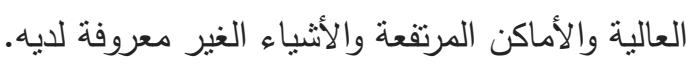

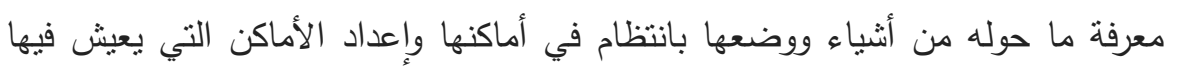

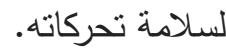
تعلم العادات المقبولة كالأكل بطريقة مهذبة واستخدام المائدة وتتظيف الأسنان والتعرف علي أدوات الحمام وأماكنها واستخدامها. مشكلات المكفوفين: تتتوع المشكلات التي يعاني منها المكفوفين فبعضها يرجع إلى الفرد نفسه

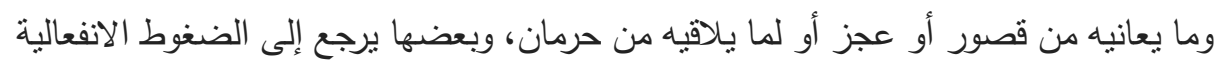

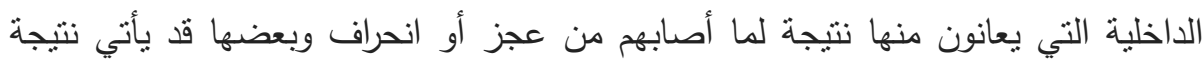
للظروف الاجتماعية السيئة والعلاقات الاجتماعية غير السوية التي يعيشون فيها أو نتيجة 
لأوضاع المجتمع ونظرته إليهم مما يعوق تكيفهم مع المجتمع ويقق دون إسهامهم الايجابي

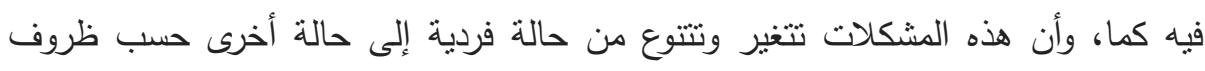

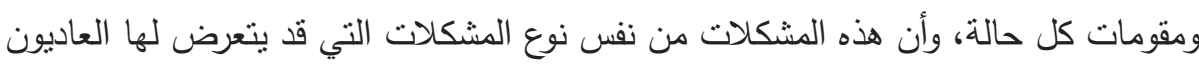

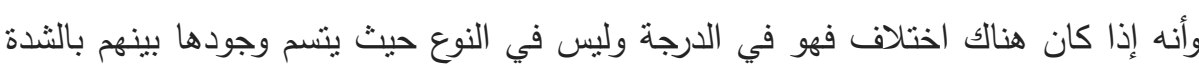
والحدة.

وأنه إذا تم تناول الدكفوفين بالعلاج والتأهيل والتوجيه السليم فإنه بمكن الحد من وجود

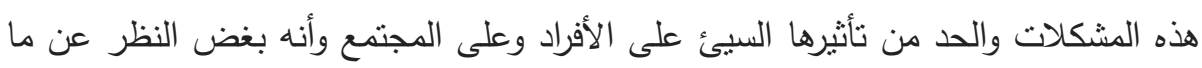

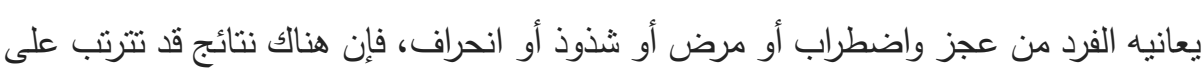

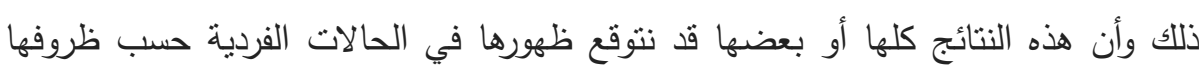
ومقوماتها.

وبغض النظر عن نوع الفئات المختلفة سواء كانت نتعلق بالناحية الجسمية أو النفسية

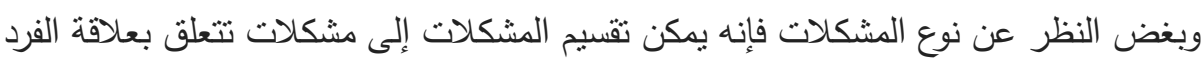

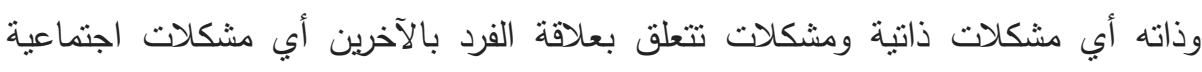
ومشكلات تتعلق بالكفاية الإنتاجية.

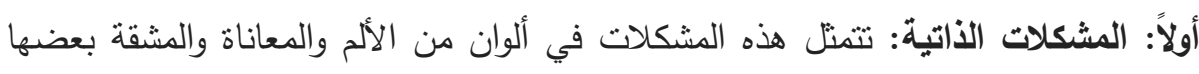

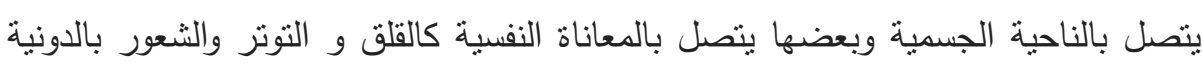
والتعاسة أو عدم القدرة على التوافق ، سواء بينه أو بين نفسه أو بينه وبين الآخرين أو بينه بينه

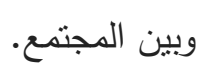

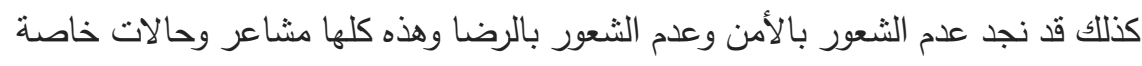

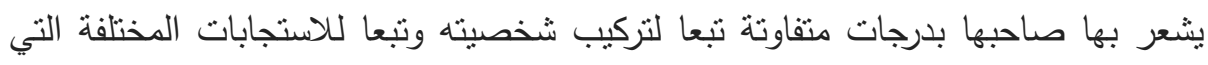

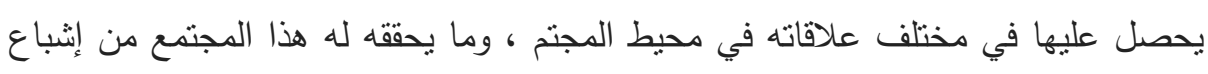
لحاجاته وما يوفره له من رعاية وعناي، سواء في محيط حياته الداخلية أو الخارجية.

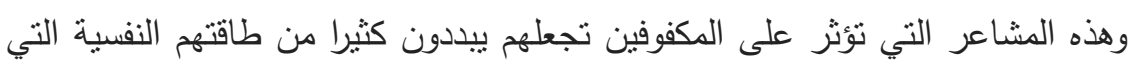

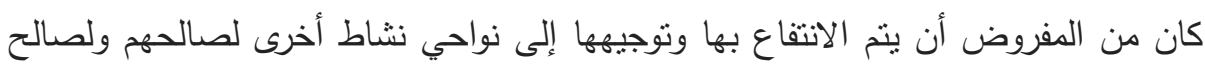

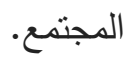


ومما لاشك فيه أن معاناة الألم في حد ذاته سواء أكان جسميا أو نفسيا أو معاناة الألم في

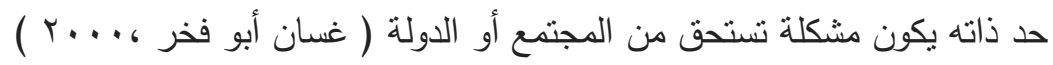

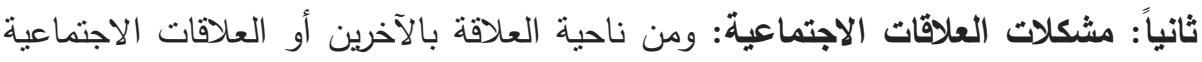

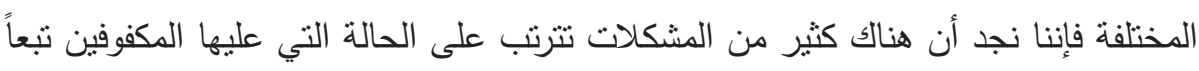
لتكوينهم النفسي وظروفهم الاجتماعية وهذه المشكلات أو النتائج يمكن أن تتمثل في مشكلات

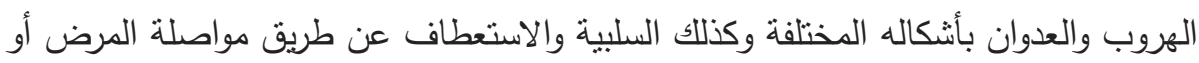

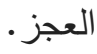

وتتمثل هذه المشكلات في تفكك العلاقات الأسرية أو اضطراب علاقات الفرد بمحيطه داخل الأسرة وخارجها أو ما يمكن تسميته بمشكلات سوء التكيف مع البيئة الاجتماعية للفرد.

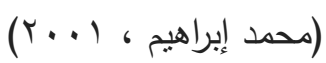

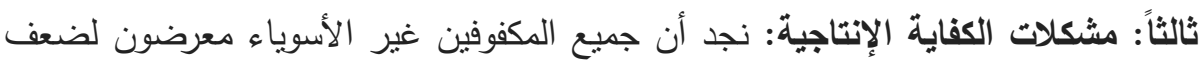

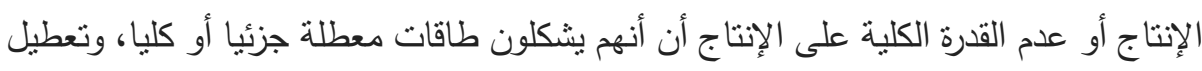

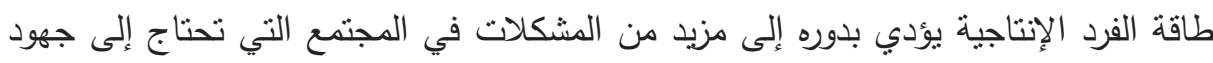
كبيرة لمواجنها والعمل لحلها. (وجدي بركات : 1. . ب ).

\section{هفاسيه الصراسمة}

• المشكلات الاجتماعية: يوجد تعريفات عديدة لمفهوم المشكلات الاجتماعية حيث عرفها مختار محمد عبد اللا وآخرون بأنها ظاهرة اجتماعية يعتقد إن وجودها واستمرارها غير

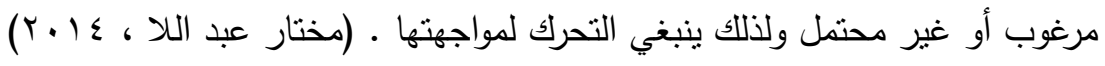
كما يمكننا أن نعرف المشكلات الاجتماعية إجرائياً على أنها:

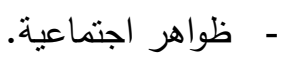
- - تعتبر أوضاع أو أحوال ينظر لها المجتمع على أنها تهديد لوجوده الصحيح.

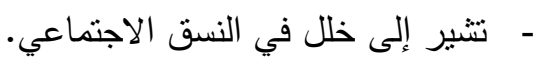
- - مهي المفارقات بين المستويات المرغوبة والظروف الواقعية. 


$$
\text { - - ت تعتبر عن وجود احتياجات غير مشبعة. }
$$

الكفيف: عرفته نظيمة أحمد محمود سرحان على أنه هو الشخص الذي لا بستطيع أن يجد

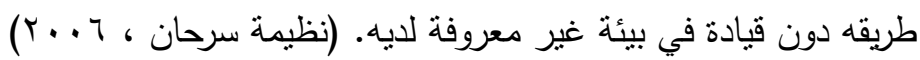

$$
\begin{aligned}
& \text { يمكن تعريف الكفيف إجرائيًا على أنه: }
\end{aligned}
$$

- - الثخص غير القادر على رؤية الأشياء بالعين المجردة ولا حتى بالنظارات الطبية.

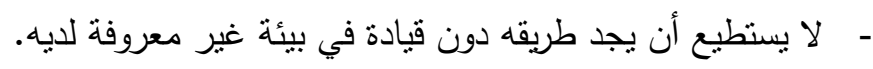

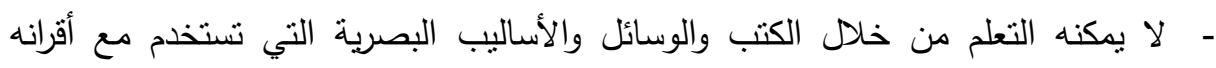

$$
\begin{aligned}
& \text { المبصرين في العمر الزمني نفسه. } \\
& \text { - يعتمد على حواس أخرى غير البصر كالسمع في اكتساب المعرفة. } \\
& \text { - - - يحتاج إلى طرق ووسائل وأدوات تعليمية خاصئ. } \\
& \text { - مكنه تعلم القراءة والكتابة فقط بطريقة برايل. }
\end{aligned}
$$

• الدور: عرفه محمد الجوهري على أنه عبارة عن مجموعة مركبة من القواعد العامة. (محمد برائ

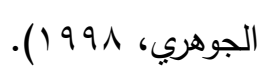

كما بمكن تعريفه إجرائيًا على أنه:

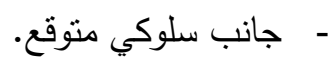

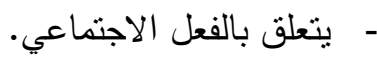

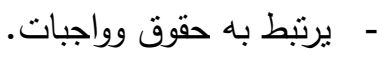

- - وهو مجموعة مركبة من الحقائق العامة.

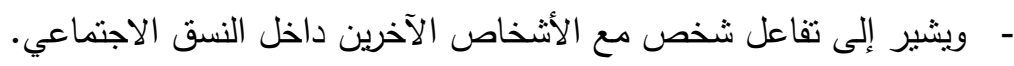

- ميرتبط بشخص يشغل وضعًا اجتماعيًا معينًا.

• الجمعيات الأهلية: يعرفها رشاد أحمد عبد اللطيف بأنها تلك المنظمات التي تقوم على لثى

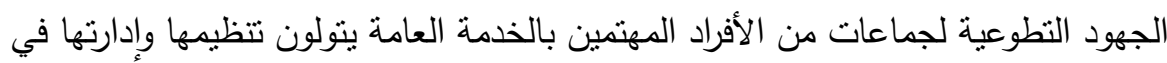

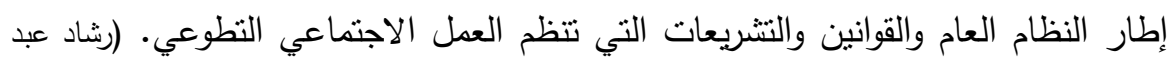

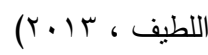




\section{إلجراءائ الهمهث}

منهج الدراسة : تعنبر الدراسة الحالية من الدراسات الوصفية والتي تستخدم كلاً من الدناهج التالية: المنهج الوصفي، الأسلوب الإحصائي لمعالجة البيانات

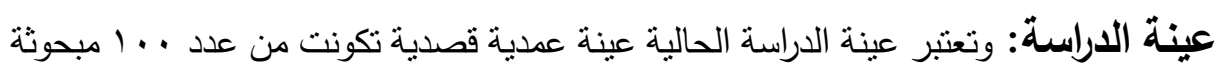
من الكفيفات اللاتي يتلقين تعليم جامعي في الجامعات الحكومية بإقليم القاهرة الكبرى كالتالي: جدول(1 ): نوزيع العينة وفقا للجامعة المنتسبين لها هاني

\begin{tabular}{|c|c|c|}
\hline النسبة المئوية & التكرار & \\
\hline 71 & 71 & جامعة حلوان \\
\hline 0 & 0 & جامعة عين شمس \\
\hline 0 & 0 & جامعة القاهرة \\
\hline 10 & 10 & جامعة الأزهر \\
\hline$r$ & $r$ & جامعة بنها \\
\hline$\varepsilon$ & $\varepsilon$ & معهد كونسرافتوار \\
\hline $1 \ldots$ & $1 \ldots$ & المجموع \\
\hline
\end{tabular}

ييين الجدول رقم 1 عن توزيع العينة وفقا للجامعة المنتسب إليها.

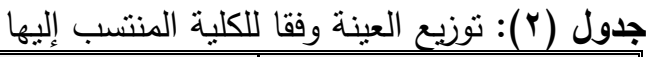

\begin{tabular}{|c|c|c|}
\hline النسبة المئوية & التكرار & \\
\hline $7 \pi$ & $7 \pi$ & الآداب \\
\hline 19 & 19 & السن \\
\hline 7 & 7 & دار العلوم \\
\hline$r$ & $r$ & علوم \\
\hline$r$ & $r$ & دراسات إسلامية \\
\hline 1 & 1 & تجارة \\
\hline 1 & 1 & الإعلام \\
\hline$T$ & 1 & حقوق \\
\hline 1 & 1 & سياحة وفنادق \\
\hline 1 & 1 & أصول دين \\
\hline 1 & 1 & تربية \\
\hline $1 \ldots$ & $1 \ldots$ & المجموع \\
\hline
\end{tabular}




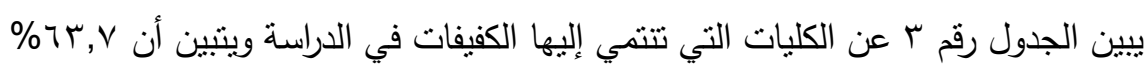

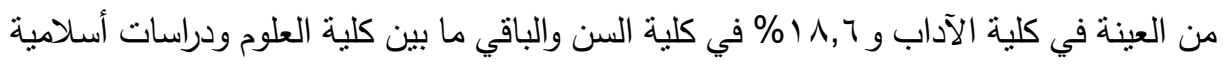
وتربية وعلوم وحقوق أدوات الدراسة: وتمنلت أهم أدوات الدراسة الحالية في صحيفة الاستبيان حول المشكلات الاجتماعية والفيزيقية للكفيفات ودور الجمعيات الأهلية في مواجهتها (في مرحلة التعليم الجامعي)

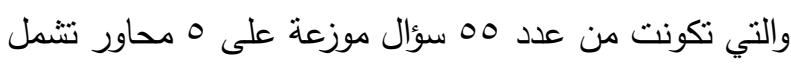
- - البيانات الأساسية.

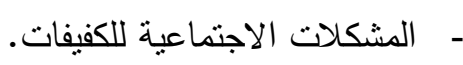
- - المشكلات الفيزيقية للكفيفات. - - دور الجمعيات الأهلية في مواجهة المشكلات الاجتماعية للكفيفات. - دور الجمعيات الأهلية في مواجهة المشكلات الفيزيقية للكفيفات. وقد تم تطبيق الصحيفة على الكفيفات اللاتي يترددن على جمعيات أهلية ويدرسون في

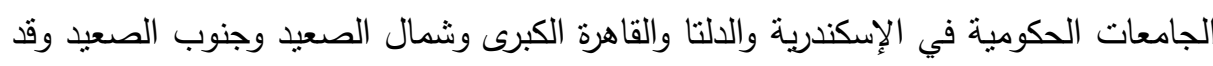

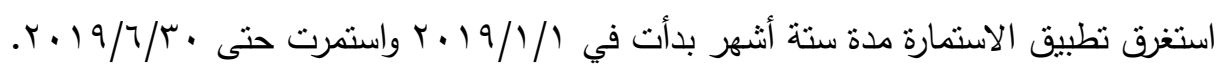

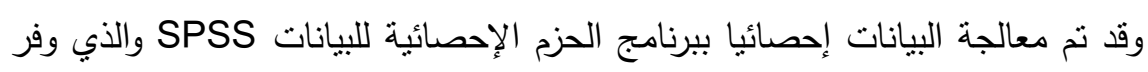

$$
\text { لنا جداول بسيطة وجداول مركبة. }
$$

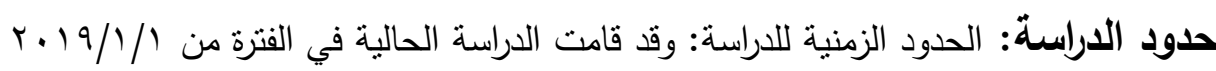

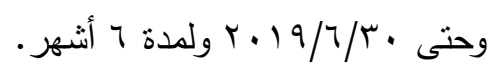

الحدود المكانية للاراسة: وقد شملت الدراسة على عينة مكونة من الكفيفات المنتميات للجمعيات الأهلية واللاتي يدرسن في الجامعات المصرية بإقليم القاهرة الكبرى (القاهرة - الجيزة

$$
\text { - القليوبية). }
$$

ولقد قامت الدراسة الحالية باستخدام صحيفة الاستبيان كأداة أساسية للاراسة، مع استخدام المكالمات الهاتفية وذللك لتطبيق الصحيفة. 
واعتمدت الدراسة على معايير صدق وثبات لصحيفة الاستبيان والتي من إعداد الباحثة

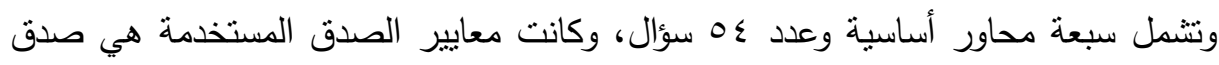
المحكمين حيث نم عرض الصحيفة على المختصين واللذين قاموا بإجراء التعديلات عليها ثم أث

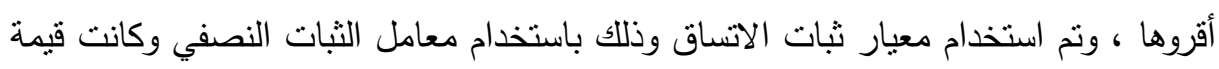

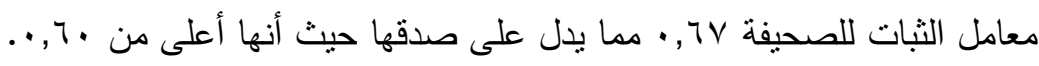

\section{نتمأيج الصراسلة}

وفيما يلي عرض موجز لنتائج الدراسة نتبعه بتعليق سريع عليها كما يلي: جدول (ץ): هل توجد كتب بالمكتبة خاصة بالمكفوفين مسموعة برايل

\begin{tabular}{|c|c|c|}
\hline النسبةً المئوية & التكرار & \\
\hline$\varepsilon r$ & $\varepsilon r$ & نعم \\
\hline ov & ov & $y$ \\
\hline $1 \ldots$ & $1 \ldots$ & المجموع \\
\hline
\end{tabular}

يبين الجدول رقم ع عن أولى المشكلات التعليمية للكفيفات فنجد أن 00,9\% من إجمالي العينة لا يتوفر لايها كتب تتاسب الكفيفات سواء بطريقة برايل أو كتب مسموعة فحين أن نسبة التبات

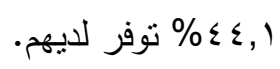
جدول (؛ ): تقديم استثناءات للكفيفات من موظفى الجامعات المصرية

\begin{tabular}{|c|c|c|c|c|c|c|c|c|c|c|c|c|c|c|}
\hline \multicolumn{2}{|c|}{ Total } & \multicolumn{2}{|c|}{ كونسرافتوار } & \multicolumn{2}{|c|}{ جنها } & \multicolumn{2}{|c|}{ الأزهرة } & \multicolumn{2}{|c|}{ القاهرة } & \multicolumn{2}{|c|}{ شامعة } & \multicolumn{2}{|c|}{ جامعة } & \\
\hline$\%$ & ك5 & $\%$ & ك & $\%$ & ك & $\%$ & ك5 & $\%$ & ك5 & $\%$ & ك5 & $\%$ & ك & \\
\hline 75 & 77 & 100 & 4 & 33 & 1 & 53 & 8 & 100 & 5 & 100 & 5 & 78 & 53 & نعم \\
\hline 25 & 25 & 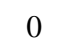 & 0 & 67 & 2 & 47 & I & 0 & 0 & 0 & 0 & 22 & $1^{\circ}$ & $y$ \\
\hline 100 & 10. & 100 & 4 & 100 & 3 & 100 & 15 & 100 & 5 & 100 & 5 & 100 & 685 & \\
\hline & & r & $=$ & & & & & & & 11,0 & $\cdot=$ & & & \\
\hline
\end{tabular}

يبين الجدول رقم 0 عن وجود علاقة ذات دلالة إحصائية ضعيفة بين مدى وجود

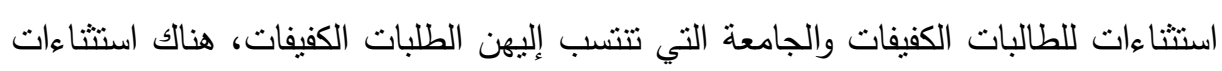


تقدم في جامعة حلوان الصعيد وجامعة الأزهر تصل إلى ..1\% فحين تتخفض في باقي

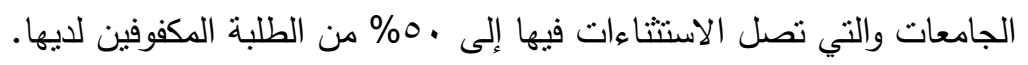

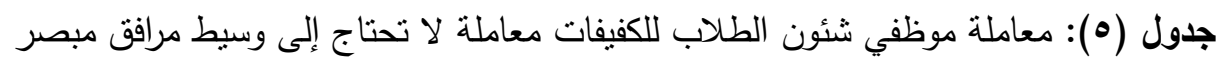

\begin{tabular}{|c|c|c|}
\hline النسبة المئوية & التكرار & \\
\hline $7 \varepsilon$ & $7 \varepsilon$ & نعم | لن \\
\hline$r 4$ & $r 4$ & $y$ \\
\hline $1 \ldots$ & $1 \ldots$ & لمجموع الموع \\
\hline
\end{tabular}

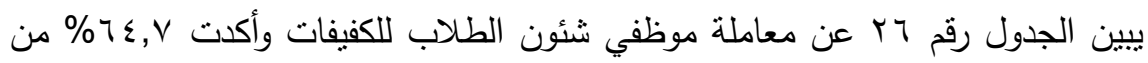

العينة على أن المعاملة معهم لا تحتاج إلى وسيط بينهم أي أن المعاملة جيدة وهناك تفهم وسرعة

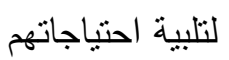
جدول (؟): معاملة موظفى شئون الطلاب فى الجامعات المصرية للطلبة الكفيفات

\begin{tabular}{|c|c|c|c|c|c|c|c|c|c|c|c|c|c|c|}
\hline \multicolumn{2}{|c|}{ Total } & \multicolumn{2}{|c|}{ كونسررافتوار } & \multicolumn{2}{|c|}{ جنامعة } & \multicolumn{2}{|c|}{ الأزهرة } & \multicolumn{2}{|c|}{ القفامرة } & \multicolumn{2}{|c|}{ شمامعة } & \multicolumn{2}{|c|}{ خامعة } & \\
\hline$\%$ & ك & $\%$ & ك & $\%$ & كs & $\%$ & ك & $\%$ & ك & $\%$ & ك & $\%$ & ك & \\
\hline $\mathrm{v} 7$ & 77 & 100 & 4 & 33 & 1 & 53 & 8 & 100 & 5 & 100 & 5 & 87 & 35 & קعم \\
\hline 25 & 25 & 0 & 0 & 67 & 2 & 47 & 7 & 0 & 0 & 0 & 0 & 22 & .1 & V \\
\hline 100 & $\cdot 10$ & 100 & 4 & 100 & 3 & 100 & 15 & 100 & 5 & 100 & 5 & 100 & 68 & \\
\hline
\end{tabular}

يين الجدول رقم \ والذي يبين عن معاملة موظفي شُئون الطلاب في الجامعات الدصرية

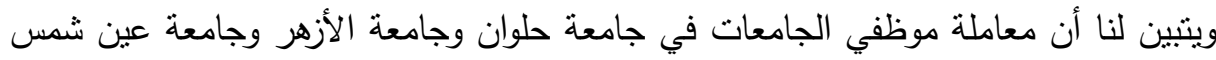

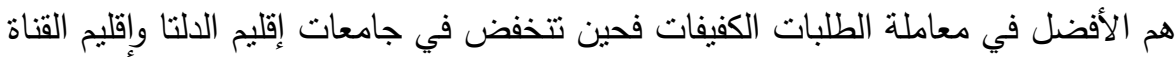
جدول (v): التواصل بين الكفيفات وموظفى الجامعات المصرية

\begin{tabular}{|c|c|c|c|c|c|c|c|c|c|c|c|c|c|c|}
\hline \multicolumn{2}{|c|}{ Total } & \multicolumn{2}{|c|}{ كونسرافتوار } & \multicolumn{2}{|c|}{ جامعة } & \multicolumn{2}{|c|}{ جالأزهرة } & \multicolumn{2}{|c|}{ جامعة القاهرة } & \multicolumn{2}{|c|}{ شعبن } & \multicolumn{2}{|c|}{ جامعة } & \\
\hline$\wedge 5$ & 58 & 25 & 1 & 67 & 2 & 53 & 8 & 80 & 4 & 80 & 4 & 56 & 38 & نعم \\
\hline$\leq 4$ & 44 & 75 & 3 & 33 & 1 & 47 & 7 & 20 & 1 & 20 & 1 & 44 & 30 & $y$ \\
\hline 100 & $\cdot 10$ & 100 & 4 & 100 & 3 & 100 & 15 & 100 & 5 & 100 & 5 & 100 & 68 & \\
\hline
\end{tabular}


يين الجدول رقم ^ عن التواصل بين الكفيفات وبين موظفي الجامعات المصرية في إقليم القاهرة الكبرى نجد أن هناك نواصل شبة مستمر بين الموظفين والطالبات الكفيفات في جامعة

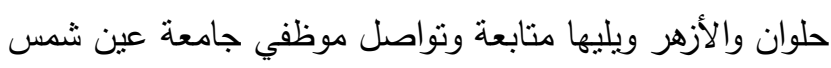

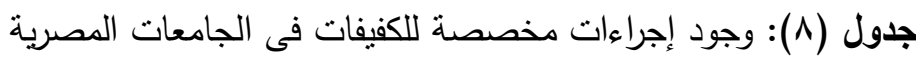

\begin{tabular}{|c|c|c|c|c|c|c|c|c|c|c|c|c|c|c|}
\hline \multicolumn{2}{|c|}{ Total } & \multicolumn{2}{|c|}{ كونسرافتوار } & \multicolumn{2}{|c|}{ جنها } & \multicolumn{2}{|c|}{ الأزهز } & \multicolumn{2}{|c|}{ جامعة } & \multicolumn{2}{|c|}{ شامعة } & \multicolumn{2}{|c|}{ جامعة } & \\
\hline$\%$ & ك & $\%$ & ك5 & $\%$ & ك & $\%$ & ك5 & $\%$ & ك5 & $\%$ & ك5 & $\%$ & ك5 & \\
\hline 40 & 40 & 0 & 0 & 67 & 2 & 67 & 10 & 20 & 1 & 60 & 3 & 03 & 42 & نعم \\
\hline 60 & 60 & 100 & 4 & 33 & 1 & 33 & 5 & 80 & 4 & 40 & 2 & ${ }^{\circ 6}$ & 44 & $y$ \\
\hline 100 & $\cdot 10$ & 100 & 4 & 100 & 3 & 100 & 15 & 100 & 5 & 100 & 5 & 100 & 68 & المجموع \\
\hline
\end{tabular}

يبين الجدول رقم 9 عن مدى وجود إجراءات مخصصة للكفيفات في جامعات القاهرة الكبرى، نجد أن جامعة حلوان هي الأكثر نوفيرا لمتل هذه الإجراءات والتي تساهم في تخفيف

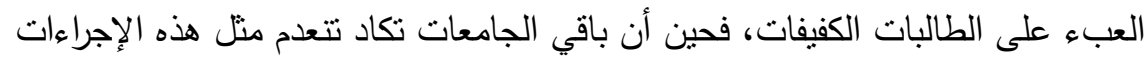
جدول (9): هل ينظر إليهن موظفي الجامعة نظرة شفقة أو دونية

\begin{tabular}{|c|c|c|}
\hline النسبة المئوية & التكرار & \\
\hline$r 0, r$ & rq & نعح \\
\hline$T \varepsilon, V$ & 77 & $y$ \\
\hline $1 \ldots$ & $1 \cdot r$ & المجموع \\
\hline
\end{tabular}

يين الجدول رقم ·1 عن مدى وجود نظرة شفقة أو دونية من موظفي الجامعة وتؤكد

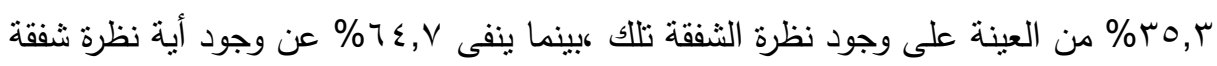
منهم تجاه الكفيفات. تعليق عام على النتائج: يمكن النظر للمشكلة الراهنة على أنها عدم قدرة الجمعيات الأهلية على مواجهة المشكلات الاجتماعية والفيزيقية للكفيفات، ويمكن مواجهة هذه المشكلة من خلال النظرية البنائية الوظيفية من خلال عدة محاور نذكر منها على سبيل المنال لا الحصر ما يلي: 
- يجب ان تتكامل كل الأجزاء للجمعيات الأهلية سواء كانت المادية كالأجهزة والأدوات والإداريين والمباني والتمويل وغيرها، أو المعنوية كاللوائح والقوانين والتنظيم وغيرها في التيه

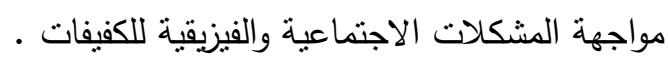

- الوفاء باحتياجات الجمعيات الأهلية كي تتمكن من مواجهة المشكلات الاجتماعية والفيزيقية للكفيفات.

- دعم الأجزاء الوظيفية للجمعيات الأهلية والتي تسهم في تحقيق توازن الجمعية الأهلية كنسق

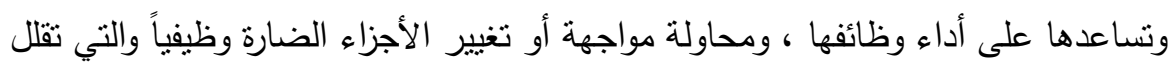
من توازن الجمعية الأهلية كنسق وتضر بها ، والتقليل قدر الإمكان من الأجزاء غير الوظيفية الواهية

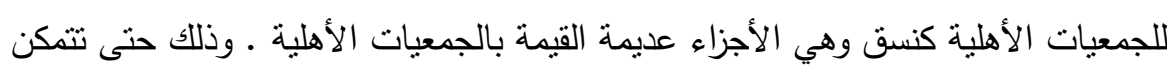
الجمعيات الأهلية من مواجهة المشكلات الاجتماعية والفيزيقية للكفيفات.

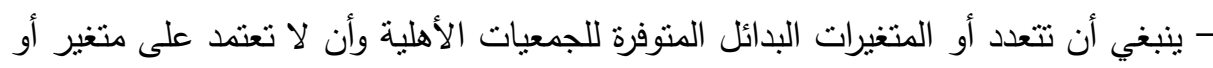
بديل واحد في إنباع حاجاتها وفي طرق مواجهة المشكلات الاجتماعية والفيزيقية للكفيفات. - أظهرت النتائج أن أغلب العينة لا توجد بمكتباتهن الجامعية كتب مسموعة أو مكتوبة بطريقة برايل ، ويمكننا أن نفسر ذلك في ضوء عدم وجود مراكز متخصصة بالجامعات تمنل الطلبة

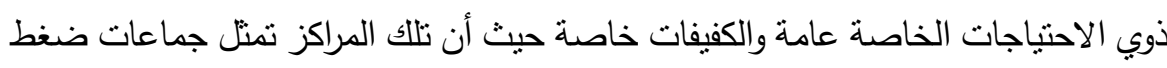
للمطالبة باحتياجات الكفيفات ، وأيضاً زيادة اهتمام الجامعات بالعملية التعليمية الأساسية

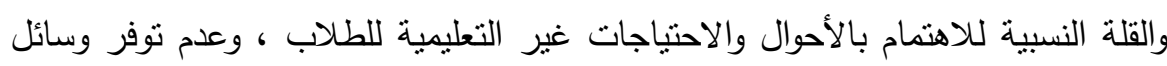
تعليمية مناسبة ، وقلة التمويل في الجامعات الموجه إلى احتياجات فئات معينة من الطلبة.

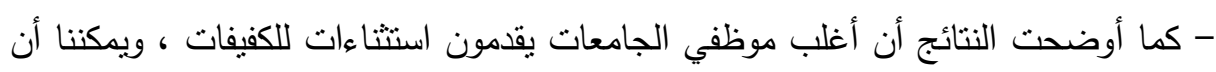
نفسر ذلك في ضوء طبيعة ثقافة المجتمع المصري والمحرك الديني لدى المواطنين حيث أنه وعلى الرغم من عدم وجود لوائح صريحة تشير لتقديم استثاءات للكفيفات إلا أن القيم

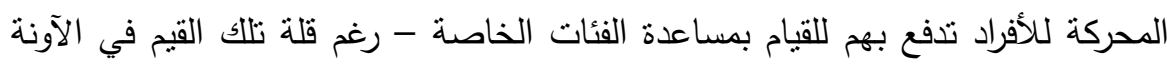
الأخيرة - كما يمكننا تفسير ذلك أيضاً لتقبل الطلاب غير المكفوفين لتقديم الموظفين استثاءات لزميلاتهم الكفيفات. 
- وأوضحت النتائج إن معاملة موظفي شئون الطلاب لأغلب العينة لا تحتاج إلى وسيط "مرافق مبصر" ويمكننا تفسير ذللك إلى أن الطالبات الكفيفات غالباً ما يسعون للاستقلالية مما يدفع لئح بهن إلى محاولة التعامل وتوضيح المطلوب منهم ، كما يمكننا تفسير ذلك بناءاً على تفهم الموظفين للظروف التي تمر بها الكفيفات مما يجعلهم يمضون وقتاً أطول في محاولة فهم احتياجات الكفيفات وتلبية رغباتهن.

- وبينت النتائج حسن معاملة موظفي شئون الطلاب للكفيفات لدى أغلب العينة، ويمكننا أن نرجع ذللك للقيم السائدة لدى مواطنو المجتمع المصري والوازع الديني لديهم، وكما أشرنا سابقاً فقد يرجع ذلك أيضاً لمحاولة الموظفين قضاء وقت أطول مع الكفيفات مما يتيح للموظفين تلبية حاجات الكفيفات، ويعود ذلك على الكفيفات بالشعور بحسن معاملة موظفي شُئون الطلاب لهن.

- وأوضحت النتائج أن نصف العينة تقريباً لا يتواصلون مع موظفي شئون الطلاب بجامعاتهن،

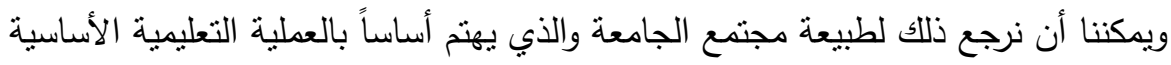

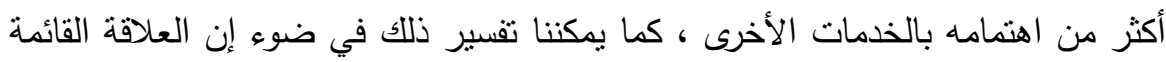
بين الكفيفات وموظفي شئون الطلاب هي علاقة مهنية وليست علاقة شخصية، وتقوم

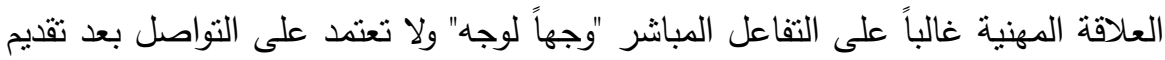

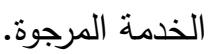

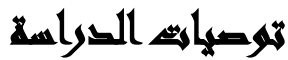

\section{أ. فيما يخص الجمعيات الأهلية:}

- - سن نتريعات ثابتة تتظم عمل الجمعيات الأهلية مع الكفيفات.

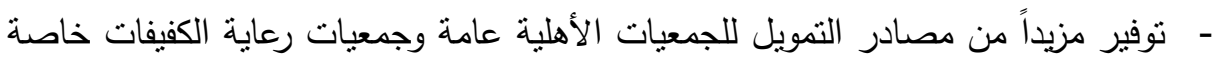
حتى تتمكن من إثباع احتياجات الكفيفات ومواجهة مشكلاتهن. - ضرورة التتسيق بين الجمعيات الأهلية عامة والتي تعني بمشكلات الكفيفات خاصة فيما بينهم وذللك لتحسين حصول الكفيفات على خدمات تلك الجمعيات. 
- وضع برامج تدريبية للمتطوعين المبصرين الذين يتعاملون مع الكفيفات كي يستطيعون

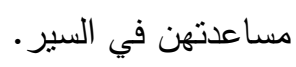

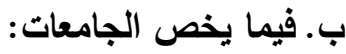

- توفير المزيد من الكتابات بطريقة برايل أو كتب مسموعة لمساعدة الكفيفات على التحصيل

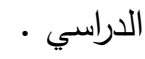

- - تدريب الإداريين بالجامعات للتعامل مع الكفيفات حسب طبيعة إعاقتهن. - - إنشاء وتقعيل مركز خاص للكفيفات يقوم بدور الوساطة بينهن وبين الجامعة يسهل لهن

الحصول على الخدمات الجامعية المختلفة ويسهل عليهن العملية التعليمية.

- فتح قنوات تواصل بين موظفي الجامعات المصرية وبين الكفيفات سواء عن طريق الأنترنت أو عن طريق مراكز خدمات جامعية للكفيفات أو غيرها من الطرق.

- - سن نشريعات مناسبة نساعد الكفيفات في الحصول على خدماتهن الجامعية ، مما يؤدي إلى وجود إجراءات مناسبة للكفيفات في الجامعات المصرية.

- تدريب موظفي شئون الطلاب بالجامعات المصرية على كيفية التعامل مع الكفيفات ، مما يؤدي إلى تغيير نظرة موظفي شُئون الطلاب تجاه الكفيفات.

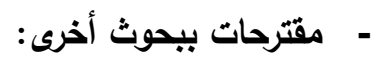

- إجراء مزيد من الدراسات اللاحقة حول مشكلات الكفيفات وسبل حلها في كافة النواحي الأخرى

- - إجراء دراسات لاحقة عن المشكلات الاجتماعية للكفيفات في مختلف المراحل العمرية

$$
\text { والتعليمية. }
$$

\section{هراليع المهيث}

أنتوني ج· بيلون، نرجمة: نظيرة حسن، ومراجعة وتقديم: محمد السيد روحه: تعليم المعوقين

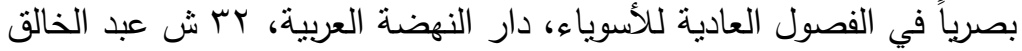

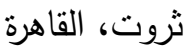

بهاء محمد حجاج مصطفى- تطور مراكز الرعاية لذوي الإعاقة البصرية بالجامعات المصرية

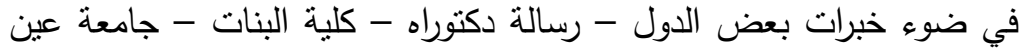

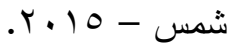




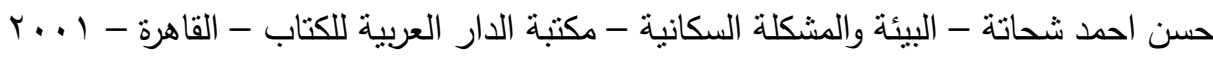
دعاء كرم محد علي - برنامج إرشادي (معرفي سلوكي) للتخفيف من حدة الرهاب الاجتماعي

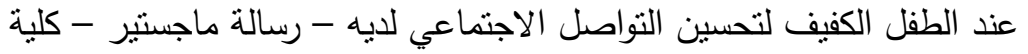

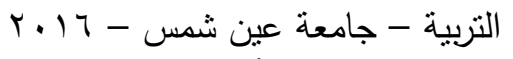

رانيا عبد المعز الجمال: تعليم الأطفال المكفوفين بين الواقع والمأمول، دار الجامعة الجديدة

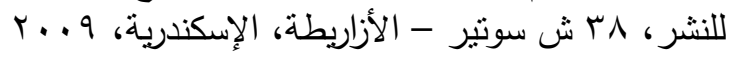

رشاد أحمد عبد اللطيف وآخرون - ممارسة الخدمة الاجتماعية الريفية والحضرية - مكتبة

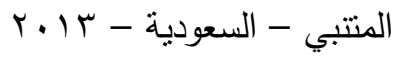

سامية فيصل حسن يوسف، قياس فعالية برنامج حاسوبي مقترح لتتمية مهارات استخدام المكتبات

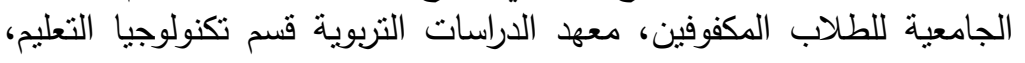

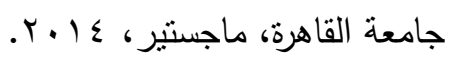

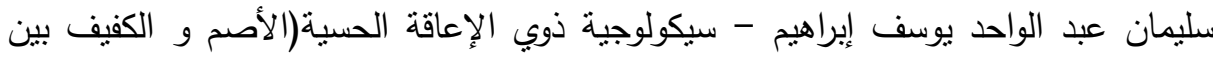

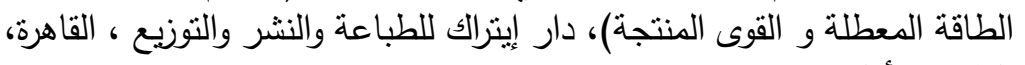

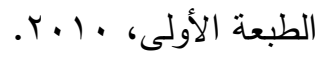

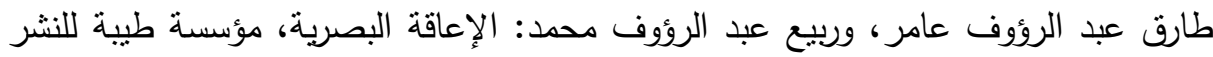

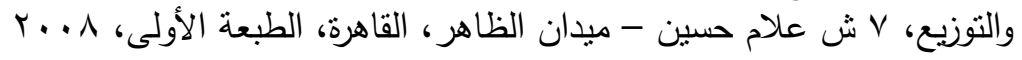

عبد الله أحمد أحمد جوده، دراسة مقارنة بين عينة من المكفوفين المقيمين فى المؤسسة والمقيمين

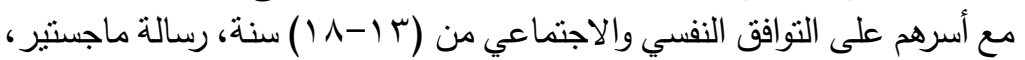

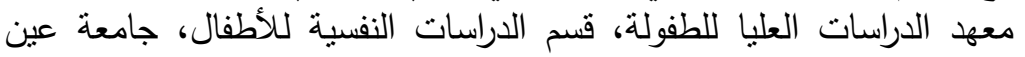

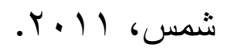

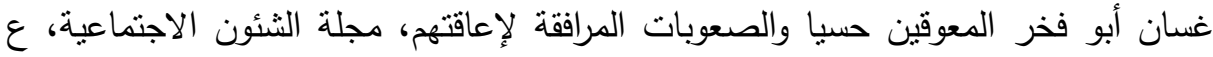

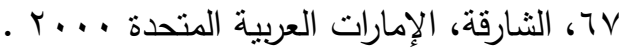

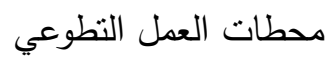

http://www.paldf.net/forum/showthread.php?t=10100251-1

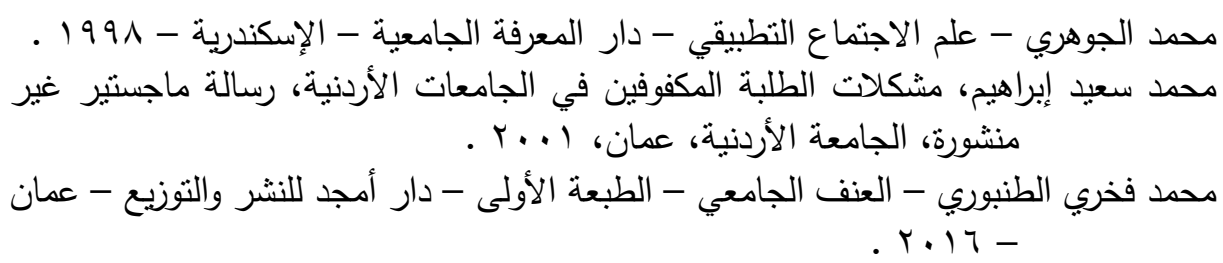




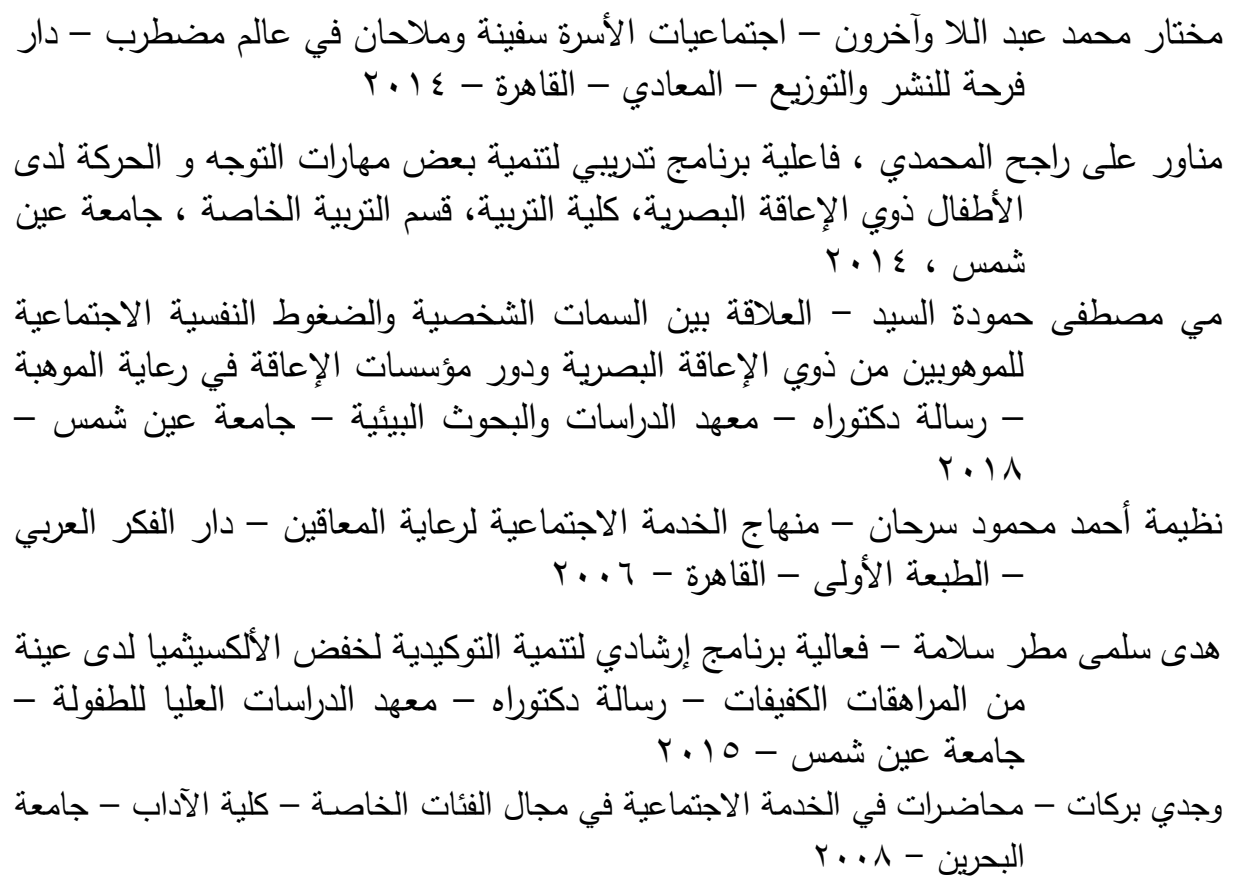

Salinee Kuakiatwong,Evaluating web accessibility and usability for totally blind users , at Thailand Cyber University, $\mathrm{PhD}$, School of Education, 2011

Siddhi R. Vyas -Reconstitution and implementation of national education policy through state-NGO collaboration: Inclusion education in policy and primary school practice for the blind in India, submitted in partial fulfillment of the requirements for the degree of Doctor of Education in teachers college, Colombia University, 2010 


\title{
SOCIAL AND PHYSICAL PROBLEMS OF THE BLIND FEMALES AND THE ROLE OF NGOS - UNIVERSITY EDUCATION STAGE
}

Faten I. A. A.El-Gendy ${ }^{(1)}$; Ali M. Laila ${ }^{(2)}$; Soheir A. Elattar ${ }^{(3)}$ Mohamed A. Mahrous ${ }^{(4)}$ and Hala R. Ali ${ }^{(5)}$

1) Post Grad. Institute of Environmental Studies and Research, Ain Shams University 2) Faculty of Arts, Ain Shams University 3) Faculty of girls, Ain Shams University 4) Faculty of Arts, Helwan University 5) National Center for Social and Criminological Research

\begin{abstract}
The present study examines both the social and physical problems of blind women and the role of NGOs in confronting them and to address the roles of NGOs.

The main problem of the research was the social and physical problems facing the blind and the role of NGOs in facing them.

The current study used the descriptive method and statistical method on a sample of 100 blind students from public universities who are attending NGOs. The study lasted for 6 months from January 2019 to June 2019 using a questionnaire as the main tool for collecting study data. The study reached several results, the most important of which are:

- The current problem can be seen as the inability of NGOs to address the social problems of blind women.

- The inability of NGOs to face the physical problems of blind women.

- Lack of books in the library for the visually impaired in Braille.

- Lack of procedures for blind women in Egyptian universities.
\end{abstract}

Key words: Social problems - Environmental problems - PHYSICAL PROBLEMS- BLIND FEMALES - BLIND - university education NGOS. 